\title{
Immunomodulatory activity of polysaccharides isolated from Clerodendrum splendens: Beneficial effects in experimental autoimmune encephalomyelitis
}

Koffi Kouakou ${ }^{1,2+}$, Igor A Schepetkin ${ }^{1 \dagger}$, SangMu Jun ${ }^{3}$, Liliya N Kirpotina ${ }^{1}$, Ahoua Yapi ${ }^{4}$, Daria S Khramova ${ }^{5}$, David W Pascual ${ }^{3}$, Yury S Ovodov ${ }^{5}$, Mark A Jutila ${ }^{1}$ and Mark T Quinn ${ }^{1 *}$

\begin{abstract}
Background: Extracts of leaves from Clerodendrum have been used for centuries to treat a variety of medicinal problems in tropical Africa. However, little is known about the high-molecular weight active components conferring therapeutic properties to these extracts.
\end{abstract}

Methods: Polysaccharides from the leaves of Clerodendrum splendens were extracted and fractionated by ion exchange and size-exclusion chromatography. Molecular weight determination, sugar analysis, degree of methyl esterification, and other chemical characterization of the fractions were performed. Immunomodulatory activity of the fractions was evaluated by determining their ability to induce monocyte/macrophage nitric oxide (NO), cytokine production, and mitogen-activated protein kinase (MAPK) phosphorylation. Experimental autoimmune encephalomyelitis (EAE) was induced in C57BL/6 mice, and severity of EAE was monitored in mice treated with intraperitoneal (i.p.) injections of the most active polysaccharide fraction. Lymph nodes $(L N)$ and spleen were harvested, and levels of cytokines in supernatants from LN cells and splenocytes challenged with myelin oligodendrocyte glycoprotein peptide were determined.

Results: Fractions containing type II arabinogalactan had potent immunomodulatory activity. Specifically, the high-molecular weight sub-fraction CSP-AU1 (average of $38.5 \mathrm{kDa}$ ) induced NO and cytokine [interleukin (IL)-1a, -1 $3,-6,-10$, tumor necrosis factor (TNF; designated previously as TNF-a), and granulocyte macrophage-colony stimulating factor (GM-CSF)] production by human peripheral blood mononuclear cells (PBMCs) and monocyte/macrophages.

CSP-AU1-induced secretion of TNF was prevented by Toll-like receptor 4 (TLR4) antagonist LPS-RS, indicating a role for TLR4 signaling. Treatment with CSP-AU1 also induced phosphorylation of a number of MAPKs in human PBMC and activated AP-1/NF-KB. In vivo treatment of mice with CSP-AU1 and CSP-NU1 resulted in increased serum IL-6, IL-10, TNF, monocyte chemoattractant protein-1 (MCP-1), macrophage inflammatory protein (MIP)-1a/CCL3, and MIP-1 $\beta / C C L 4$. CSP-AU1 treatment of mice with EAE $(50 \mathrm{mg} / \mathrm{kg}$, i.p., daily, 13 days) resulted in significantly reduced disease severity in this experimental model of multiple sclerosis. Levels of IL-13, TNF, interferon (IFN)- $\gamma$, IL-17, and GM-CSF were also significantly decreased, whereas transforming growth factor (TGF)- $\beta$ was increased in LN cells from CSP-AU1-treated EAE mice.

Conclusions: Polysaccharide CSP-AU1 is a potent natural innate immunomodulator with a broad spectrum of agonist activity in vitro and immunosupressive properties after chronic administration in vivo.

Keywords: Clerodendrum splendens, Polysaccharide, Macrophage, Cytokine, Immunomodulation

\footnotetext{
* Correspondence: mquinn@montana.edu

${ }^{\dagger}$ Equal contributors

'Department of Immunology and Infectious Diseases, Montana State University, Bozeman, MT 59717, USA

Full list of author information is available at the end of the article
} 


\section{Background}

Natural products comprise one of the most popular sources of complementary and alternative medicines for treating inflammatory and immune disorders [1]. While the mechanisms of action of many plant products remain to be elucidated, further study in this area is essential for the identification of novel therapeutics with immunomodulatory activity [2]. Clerodendrum splendens belongs to the family of Lamiaceae and the genus Clerodendrum, consisting of about 400 herbs, vines, shrubs, and trees of the tropics, many of which are grown as garden plants [3-5]. The plant is a climbing evergreen bush with attractive red flowers produced during the dry seasons of the year and it is very widely distributed in tropical and subtropical regions of the world [3]. Extracts of roots, leaves, and bark from C. splendens are used in traditional medicine to treat malaria, coughs, buboes, venereal infections, including gonorrhea and syphilis, skin diseases, ulcers, rheumatism, asthma, and uterine fibroid [3,6,7]. Leaves of this plant have also been used to treat various skin diseases and as wound-healing medicine [4]. For example, the leaves of $C$. splendens have been formulated into lotion and applied to bruises and sores, and dry powdered leaves have also been applied to blisters caused by burns [4].

Antimicrobial and wound healing properties of chloroform and methanol extracts from C. splendens have been confirmed in recent pharmacological studies $[8,9]$. The volatile oil of $C$. splendens, prepared by extraction of fresh flowers with $n$-hexane, was found to be active against Staphylococcus aureus and Candida albicans [10]. Antipyretic and anti-inflammatory effects of $C$. splendens extracts have also been described [11]. C. splendens has been extensively investigated, and a number of chemical constituents, including steroids, terpenoids, flavonoids, volatile constituents, cyanogenic glycoside, alkaloids, tannins, saponins, and phenolic compounds have been isolated [3,7,12-14].

Although there are many publications describing the chemical structure and bioactive effects of small molecules isolated from C. splendens, little is known about the immunomodulatory effects of polysaccharides extracted from the leaves of this plant. Since decoction in water is the most common mode of preparation, and the most common modes of administration are oral and local application, we hypothesized that polysaccharides extracted from C. splendens could have immunomodulatory properties and contribute to the therapeutic effects of extracts from this plant. To address this question, we fractionated water-soluble polysaccharides from leaves of $C$. splendens and evaluated their immunomodulatory activities. We found that the most active Clerodendrum polysaccharide fractions contained type II arabinogalactan and had potent immunomodulatory activity in vitro and in vivo. To investigate the molecular mechanism responsible for the polysaccharide-induced immunomodulatory responses, the roles of signaling pathways including mitogen-activated protein kinase (MAPK) phosphorylation and transcription factors activating protein-1 (AP-1) and nuclear factor $\mathrm{\kappa B}$ (NF-kB) were evaluated.

\section{Methods}

\section{Plant material}

Leaves of C. splendens were collected in the Bingerville areas of Cote d'Ivoire. This plant was identified and authenticated by Dr. Aké-Assi, Emeritus Professor of Botany, using voucher specimens deposited at various periods, including voucher specimen \#16877, deposited at the National Herbarium of the National Centre of Floristique of the University of Cocody-Abidjan. Parts of plants tested were air-dried for 7-10 days at room temperature away from direct sunlight and powdered under laboratory conditions.

\section{Polysaccharide fractionation}

Ground leaves (500 g) were extracted with $3 \mathrm{~L}$ boiling distilled $\mathrm{H}_{2} \mathrm{O}$ for $1 \mathrm{hr}$, and the aqueous extracts were centrifuged at 2,500 $\times \mathrm{g}$ for $15 \mathrm{~min}$. A four-fold volume of ethanol was added to each supernatant to precipitate the polysaccharides overnight at $4^{\circ} \mathrm{C}$. The precipitates were pelleted by centrifugation, dissolved in distilled $\mathrm{H}_{2} \mathrm{O}$, centrifuged at $8,000 \times \mathrm{g}$ for $1 \mathrm{hr}$, and reprecipitated with a four-fold volume of ethanol. The supernatants were re-dissolved in distilled $\mathrm{H}_{2} \mathrm{O}$ and filtered through a $0.22 \mu \mathrm{m}$ filter and concentrated in an Amicon concentrator with a $1 \mathrm{kDa}$ PLAC membrane (Millipore, Biillerica, MA) to obtain crude extracts. The crude polysaccharide extracts were further purified using ion-exchange chromatography on a DEAE-cellulose column equilibrated with $0.05 \mathrm{M}$ Tris- $\mathrm{HCl}$ buffer $(\mathrm{pH}$ 8.0). For each fractionation, the column was eluted with equilibration buffer to obtain the crude neutral polysaccharide fraction. The bound material was eluted with equilibration buffer containing $2 \mathrm{M} \mathrm{NaCl}$. The eluates were concentrated in an Amicon concentrator with a 1 kDa PLAC membrane to obtain the crude neutral (CSPN) and acidic (CSP-A) polysaccharide fractions. These fractions were further fractionated on Diaion HP-20 absorbent resin column $(2.5 \times 20 \mathrm{~cm})$. For each fractionation, the column was eluted with distilled $\mathrm{H}_{2} \mathrm{O}$, and the eluates were lyophilized to obtain unbound fractions (designated as CSP-NU and CSP-AU). Diaion-bound polysaccharides were eluted with methanol and dried to obtain fractions CSP-NB and CSP-AB.

Fractions CSP-AU and CSP-NU were further subfractionated by size-exclusion chromatography on a Sepharose-6B column $(2.5 \times 95 \mathrm{~cm})$ eluted with distilled $\mathrm{H}_{2} \mathrm{O}$ at a flow rate of $21 \mathrm{ml} / \mathrm{hr}$. The carbohydrate elution profile was determined by the phenol- $\mathrm{H}_{2} \mathrm{SO}_{4}$ method, modified to a microplate format [15], and absorbance was 
measured at $488 \mathrm{~nm}$ using a SpectraMax Plus microplate reader (Molecular Devices, Palo Alto, CA). The polyphenol elution profile was determined by the Folin-Ciocalteu assay (see below). The relevant fractions were pooled and concentrated. Buffer salts were removed from the polysaccharide samples by repeated (6x) concentration in an Amicon concentrator (1 kDa cut-off PLAC membrane) and dilution with a 10 -fold volume of distilled $\mathrm{H}_{2} \mathrm{O}$. For analysis of biological activity, the fractions were diluted in Hanks balanced-salt solution without $\mathrm{Ca}^{2+}$ and $\mathrm{Mg}^{2+}\left(\mathrm{HBSS}^{-}\right)$to a concentration of $5 \mathrm{mg} / \mathrm{ml}$ and filtered through sterile 0.22 $\mu \mathrm{m}$ filters.

\section{Characterization of polysaccharide fractions}

Average molecular weights of the polysaccharide fractions were determined by high performance size-exclusion chromatography (HP-SEC) using a Shimadzu Class VP HPC and Shodex OHpak SB-804 HQ column $(8 \mathrm{~mm} \times$ $300 \mathrm{~mm}$ ) eluted with $50 \mathrm{mM}$ sodium citrate buffer, $\mathrm{pH}$ 7.5 , containing $0.15 \mathrm{M} \mathrm{NaCl}$ and $0.01 \% \mathrm{NaN}_{3}$ at a flow rate of $0.3 \mathrm{ml} / \mathrm{min}$. Peaks were detected using a refractive index detector (RID-10A; Shimadzu, Torrance, CA). Average molecular weights of the polysaccharide fractions were estimated by comparison with retention times of pullulan standards P-100, 50, 20, 10, and 5 (Phenomenex, Torrance, CA), which have molecular weights of 112, 47.3, 22.8, 11.8, and $5.9 \mathrm{kDa}$, respectively. Reproducibility of the retention times was typically $>98 \%$.

The presence of arabinogalactan in the samples was detected by single radial gel diffusion in 1\% agarose gels containing $100 \mu \mathrm{g} / \mathrm{ml} \beta$-glucosyl Yariv reagent, which selectively interacts with and precipitates compounds containing type II arabinogalactan structures [16]. Four $\mu \mathrm{l}$ of polysaccharide samples $(10 \mathrm{mg} / \mathrm{ml}$; w/v) were loaded into the wells, and the samples were incubated at $25^{\circ} \mathrm{C}$ for $24 \mathrm{hr}$ in a humid atmosphere. A positive reaction was indicated by a reddish circle (halo) around the well, and arabic gum ( $4 \mathrm{mg} / \mathrm{ml}$ ) (Fluka Chemie $\mathrm{GmbH}$, Germany) served as a positive control.

The total amount of polyphenols in the polysaccharide fractions was determined by the Folin-Ciocalteu assay [17]. Briefly, $250 \mu \mathrm{L}$ of Folin's phenol reagent was added to the samples dissolved in $500 \mu \mathrm{L}$ distilled water. After $3 \mathrm{~min}$ at room temperature, $1.25 \mathrm{~mL}$ of $20 \%$ sodium carbonate was added, mixed, and the mixture was allowed to stand for $40 \mathrm{~min}$. The absorbance was measured at $750 \mathrm{~nm}$ in a SpectraMax Plus microplate reader. Tannic acid from Rhus semialata (Sigma-Aldrich, St. Louis, MO) was used to generate a standard curve.

For monosaccharide analysis, the polysaccharide fractions were lyophilized and submitted for analysis to the Oklahoma Center for Glycobiology Analytical Core Lab (Oklahoma City, OK). The polysaccharide samples or background blanks were subjected to methanolysis (methanolic $2 \mathrm{M} \mathrm{HCl}, 16 \mathrm{hr}, 80^{\circ} \mathrm{C}$ ), followed by acid hydrolysis ( $2 \mathrm{M}$ trifluoroacetic acid, $4 \mathrm{hr}, 100^{\circ} \mathrm{C}$ ), and the resulting monosaccharide mixtures were analyzed by high-performance anion-exchange chromatography with pulsed amperometric detection (HPAEC-PAD) on a Dionex DX-600 HPAEC system equipped with an ED50 detector (Dionex Corporation, Sunnyvale, CA). The samples were separated on a Dionex CarboPac PA20 column eluted isocratically with $12 \mathrm{mM} \mathrm{NaOH}$ at a flow rate of $1 \mathrm{ml} / \mathrm{min}$ at $22^{\circ} \mathrm{C}$. For analysis of uronic acids, the column was eluted with $10 \mathrm{mM} \mathrm{NaOH}$ for $20 \mathrm{~min}$, followed by a gradient of $100 \mathrm{mM} \mathrm{NaOH} / 150 \mathrm{mM}$ sodium acetate $(0-100 \%$ in $45 \mathrm{~min})$. Background signals were subtracted from all samples, and individual components were quantified based on electrochemical detection relative to known standards.

The content of methoxyl groups was determined using the calibration plot for methanol, as previously described [18]. Photocolorimetry was carried out at $412 \mathrm{~nm}$. The degree of methyl esterification was calculated as the ratio of the molar amount of methanol to the molar amount of uronic acids (galacturonic and glucuronic acids) and is expressed as a molar percentage. M.W., molecular weight.

\section{Determination of endotoxin contamination}

Analyses of endotoxin concentration were performed via the kinetic method with Limulus Amebocyte Lysate (LAL) kit (GenScript, Piscataway, NJ), and samples were monitored using a SpectraMax Plus microplate reader.

\section{Cell culture}

Murine macrophage J774.A1 cells were cultured in DMEM supplemented with $10 \%$ (v/v) heat-inactivated, endotoxinfree fetal bovine serum (FBS; Atlanta Biologicals, Atlanta, GA), $100 \mu \mathrm{g} / \mathrm{ml}$ streptomycin, and $100 \mathrm{U} / \mathrm{ml}$ penicillin. Cells were grown to confluence in sterile tissue culture flasks and gently detached by scraping. Human monocytemacrophage MonoMac-6 cells (DSMZ, Germany) were grown in RPMI 1640 supplemented with 10\% (v/v) endotoxin-free FBS, $10 \mu \mathrm{g} / \mathrm{ml}$ bovine insulin, $100 \mu \mathrm{g} / \mathrm{ml}$ streptomycin, and $100 \mathrm{U} / \mathrm{ml}$ penicillin. Human monocytic THP-1Blue cells obtained from InvivoGen (San Diego, CA) were cultured in RPMI 1640 medium supplemented with $10 \%(\mathrm{v} / \mathrm{v})$ endotoxin-free FBS, $100 \mu \mathrm{g} / \mathrm{ml}$ streptomycin, 100 $\mathrm{U} / \mathrm{ml}$ penicillin, $100 \mu \mathrm{g} / \mathrm{ml}$ zeocin, and $10 \mu \mathrm{g} / \mathrm{ml}$ blasticidin $\mathrm{S}$. These cells are stably transfected with a secreted embryonic alkaline phosphatase gene that is under the control of a promoter inducible by $\mathrm{AP}-1 / \mathrm{NF}-\mathrm{kB}$.

PBMCs were purified from human blood using dextran sedimentation, followed by Histopaque 1077 gradient separation and hypotonic lysis of erythrocytes. Blood was collected from healthy donors in accordance with a protocol approved by the Institutional Review Board at Montana 
State University, and informed consent was obtained from all donors for the use of their blood in this study. PBMCs were cultured at $37^{\circ} \mathrm{C}$ in a humidified atmosphere containing $5 \% \mathrm{CO}_{2}$. Cell number and viability were assessed microscopically using trypan blue exclusion.

\section{Analysis of nitric oxide (NO) production}

J774.A1 cells were plated at a density of $1.5 \times 10^{5}$ cells/ well in a final volume of $200 \mu \mathrm{l}$ in 96-well flat-bottom tissue culture plates and incubated in medium alone or medium containing various concentrations of polysaccharide fractions or lipopolysaccharide (LPS) from Escherichia coli K-235 (Sigma Chemical Co., St. Louis, MO) as a positive control. Cells were incubated at $37^{\circ} \mathrm{C}$ in the presence of $5 \% \mathrm{CO}_{2}$ for $24 \mathrm{hr}$, and $100 \mu \mathrm{l}$ of the cell culture supernatants were removed and analyzed for nitrite using a colorimetric method with $\mathrm{NaNO}_{2}$ as the standard. Briefly, supernatants were mixed with an equal volume of Griess reagent, which was prepared by mixing one part of $0.1 \%(\mathrm{w} / \mathrm{v}) \mathrm{N}$-(1-naphthyl)ethylenediamine with one part of $1 \%(\mathrm{w} / \mathrm{v})$ sulfanilamide in $5 \%$ phosphoric acid. After $20 \mathrm{~min}$, absorbance was measured at $540 \mathrm{~nm}$ using a SpectraMax Plus microplate reader.

\section{Determination of cytokine production}

J774.A1 cells, human PBMCs, or human MonoMac-6 monocytic cells were incubated for $24 \mathrm{hr}$ in culture medium supplemented with $3 \%(\mathrm{v} / \mathrm{v})$ endotoxin-free FBS, with or without polysaccharide fractions or LPS as a positive control. Concanavalin A (Con A) from Canavalia ensiformis (Calbiochem, San Diego, CA) was also used as positive control in some experiments. Cells were plated in 96-well plates at a density of $2 \times 10^{5}$ cells in $100 \mu \mathrm{L}$ per well and incubated for $24 \mathrm{hr}$. Enzyme-linked immunosorbent assay (ELISA) kits for human tumor necrosis factor (TNF) and granulocyte macrophage-colony stimulating factor (GM-CSF), or human and mouse interleukin (IL)-6 (all from Biolegend) were used to test cytokine protein levels in the cell supernatants. Where indicated, PBMCs were pretreated with or without TLR4 antagonist LPS-RS (LPS from Rhodobacter sphaeroides; Invivogen, San Diego, CA) for $30 \mathrm{~min}$, followed by treatment with or without polysaccharide sub-fraction CSP-AU1, LPS, or $200 \mathrm{nM}$ of phorbol-12-myristate-13-acetate (PMA, Sigma-Aldrich, St. Louis, MO) for $24 \mathrm{hr}$, and TNF levels were evaluated in cell supernatants using an ELISA kit. A human cytokine Multi-Analyte ELISArray $^{\text {ma }}$ Kit (SABiosciences Corporation; Frederick, MD) was also utilized to evaluate various cytokines (IL-4, IL-6, IL-8, IL-10, IL-12, IL-17A, IFN- $\gamma$, TNF, and GM-CSF) in supernatants of PBMCs.

\section{Analysis of AP-1/NF-KB activation}

Activation of AP-1/NF- $\mathrm{kB}$ transcription factors was measured using an alkaline phosphatase reporter gene assay in THP-1Blue cells. Polysaccharide fractions or LPS $(100 \mathrm{ng} / \mathrm{ml})$ were added, and the cells $\left(2 \times 10^{5}\right.$ cells/well) were incubated for $24 \mathrm{hr}$. Alkaline phosphatase activity was measured in cell supernatants using QUANTI-Blue mix (InvivoGen). Activation of AP-1/NF$\kappa \mathrm{B}$ is reported as absorbance at $655 \mathrm{~nm}$ and compared with samples treated with positive control LPS.

\section{Cytotoxicity assay}

Cytotoxicity was analyzed with a CellTiter-Glo Luminescent Cell Viability Assay Kit (Promega, Madison, WI), according to the manufacturer's protocol. Following treatment, the cells were allowed to equilibrate to room temperature for $30 \mathrm{~min}$, substrate was added, and the samples were analyzed with a Fluoroscan Ascent FL microplate reader.

\section{Mitogen-activated protein kinase (MAPK) profile}

Analysis of the phosphorylation states of all MAPKs was performed using a human phospho-MAPK array kit Proteome Profiler ${ }^{\mathrm{Tm}}$, which is similar to immunoprecipitation and Western blot analysis (R\&D Systems, Minneapolis, MN). Human PBMCs were incubated for $60 \mathrm{~min}$ with the selected polysaccharide fractions or negative control (HBSS). The cells were rinsed with HBSS and lysed with the buffer provided. Arrays were incubated overnight at $4^{\circ} \mathrm{C}$ with lysates obtained from $3 \times 10^{6}$ cells for each sample. The arrays were washed three times with $20 \mathrm{ml}$ of the wash buffer provided and incubated for $2 \mathrm{hr}$ with the provided detection antibody cocktail containing phospho-site-specific MAPK biotinylated antibodies. The wash steps were repeated, after which the arrays were exposed to chemiluminescent reagents, and the signal was captured with an Alpha Innotech FluorChem FC2 imaging system.

\section{EAE induction and treatment}

Female 6-8 week old C57BL/6 mice (Frederick Cancer Research Facility, National Cancer Institute, Frederick, MD) were used throughout the study of experimental autoimmune encephalomyelitis (EAE). Mice were maintained under pathogen-free conditions in individual ventilated cages and were fed sterile food and water ad libitum. All animal experiments were performed in accordance with National Institutes of Health guidelines and approved by the Montana State University Institutional Animal Care and Use Committee.

For EAE induction, mice were challenged subcutaneously in the flank with $200 \mu \mathrm{g}$ of myelin oligodendrocyte glycoprotein (MOG) $35-55$ peptide (Biosynthesis, Inc., Lewisville, TX) in $100 \mu \mathrm{l}$ of incomplete Freund's adjuvant (IFA) (Sigma-Aldrich, St. Louis, MO) containing $400 \mu \mathrm{g}$ killed Mycobacterium tuberculosis (Difco Laboratories, Detroit, MI) on day 0, as described previously [19]. On 
days 0 and 2, mice were treated by intraperitoneal (i.p.) injection with $200 \mathrm{ng}$ of Bordetella pertussis toxin (List Biological Laboratories, Campbell, CA). Starting on day 4, mice were treated daily i.p. with $50 \mathrm{mg} / \mathrm{kg}$ of CSPAU1 in $100 \mu \mathrm{l}$ of phosphate buffer saline (PBS) or with $100 \mu \mathrm{l}$ of PBS (control). Mice were monitored and scored daily by a technician blinded to treatments for clinical signs of EAE using the following scoring system: 0 , normal; 1 , a limp tail; 2 , hind limb weakness; 3 , hind limb paresis; 4 , quadriplegia; 5 , moribund state.

\section{Cytokine analysis in cultures of lymph node (LN) and splenic cells}

To assess the cytokines induced, spleen and head and neck LNs were harvested at day 17 of the disease, and total mononuclear cells $\left(5 \times 10^{6}\right.$ cells $\left./ \mathrm{ml}\right)$ were cultured with 10 $\mu \mathrm{g} / \mathrm{ml}$ of $\mathrm{MOG}_{35-55}$ peptide for 4 days in a complete medium consisting of RPMI 1640 medium with the following supplements (Invitrogen-Life Technologies): $1 \mathrm{mM}$ sodium pyruvate, $1 \mathrm{mM}$ nonessential amino acids, penicillin/ streptomycin $(10 \mathrm{U} / \mathrm{ml})$, and 10\% FBS. TNF, GM-CSF, IL13 , IL-17, IFN- $\gamma$, and TGF- $\beta$ were measured from culture supernatants, as described previously [19].

\section{Statistical analysis}

Mann-Whitney $U$ test was used for statistical analysis of clinical scores in the EAE model. One-way ANOVA and Student $t$ test were performed to analyze NO and alkaline phosphatase production, MAP kinase phosphorylation, and cytokine-specific ELISA data. Results were considered statistically significant if the $p$ value was $<0.05$. The statistical analysis was performed using Prism 5 (GraphPad Software, San Diego, CA).

\section{Results}

\section{Ethnopharmacological information}

The leaves, roots and stem bark extracts of C. splendens (local name: Trokpatan) are used extensively in traditional medicine for treating many diseases in Côte d'Ivoire. To assess the importance of this plant in traditional medicine, 38 healers from the areas of Abidjan, Alépé, Bouaké, Grand-Bassam, Man, M'batto, and Tiassalé in Côte d'Ivoire were interviewed in 2010 and 2012 regarding their use of C. splendens (Table 1). Interviewees indicated that $C$. splendens is used for hemorrhoids, sinus disease, menstrual troubles, diarrhea, healing scars, and as a febrifuge and vermifuge agent. The leaves and bark are also used to treat scrofulous infection. Decoction in water (boiling) is the most common mode of preparation. The oral route and the local application are the most commonly used modes of administration. Our ethnopharmacological survey is consistent with many of the previously published uses of C. splendens in African folk medicine.

\section{Preparation and partial characterization of Clerodendrum polysaccharide fractions}

Polysaccharides obtained by ethanol precipitation of $C$. splendens extract were fractionated using DEAE-cellulose, and the resulting fractions, designated as CSP-N ( $C$. splendens polysaccharide, neutral fraction) and CSP-A (C. splendens polysaccharide, acid fraction) were further fractionated using Diaion HP-20 resin to obtain two bound (CSP-AB and CSP-NB) and two unbound (CSP-AU and CSP-NU) fractions. The acidic and neutral Diaionunbound fractions (CSP-AU and CSP-NU, respectively) were subsequently fractionated by preparative Sepharose $6 \mathrm{~B}$ size-exclusion chromatography to obtain four sub-fractions, which were selected based on the total carbohydrate and polyphenol elution profiles (designated as CSP-AU1, CSP-AU2, CSP-NU1, and CSP-NU2) (Table 2).

Analytical HP-SEC of the individual fractions showed that each fraction was represented by a single and generally symmetrical peak on the chromatogram. Based on calibration curves derived from analysis of pullulan standards, we determined average molecular weights of the polysaccharide fractions. Sequential fractionation of $C$. splendens extract by DEAE-cellulose and Diaion HP-20 gave parent fractions with relatively low molecular weights ranging from $12.0 \mathrm{kDa}$ (fraction CSP-NB) to $24.5 \mathrm{kDa}$ (fraction CSP-AU). Polysaccharides that bound to the Diaion resin had lower molecular weights in comparison with unbound polysaccharides (13.2 vs. $24.5 \mathrm{kDa}$, and 12.0 vs. $21.7 \mathrm{kDa}$, respectively). Sub-fractions CSP-AU1 and CSP-NU1, which were obtained by size-exclusion chromatography on Sepharose 6B, had relatively high molecular weights of 38.5 and $60.6 \mathrm{kDa}$, respectively (Table 2). The samples were also tested for possible endotoxin contamination using the LAL assay. All fractions contained less than $0.2 \mathrm{ng}$ endotoxin/mg of polysaccharide, which is considered to be insignificant for various bioactive products $[20,21]$.

Analysis of polyphenols showed that polyphenol content was minimal $(<1 \%)$ in neutral polysacchride fractions from C. splendens (CSP-NB, CSP-NU, and CSP-NU1), whereas all acidic fractions and the low-molecular weight neutral sub-fraction CSP-NU2 contained a relatively high polyphenol content (from 6.5 to 9.3\%). Thus, the polyphenol component of CSP-NU is enriched in the low-molecular weight sub-fraction CSP-NU2, as compared to the highmolecular weight sub-fraction CSP-NU1 (Table 2).

Analysis of the polysaccharide fractions using the Yariv test showed that Diaion-unbound fraction CSP-NU and sub-fractions CSP-AU1 and CSP-NU1 contained type II arabinogalactan, whereas fractions that bound to this resin (CSP-AB and CSP-NB), unbound fraction CSPAU, and low molecular weight sub-fractions CSP-AU2 and CSP-NU2 all tested negative for the presence of 
Table 1 Traditional Uses of Clerodendrum splendens in Côte d'Ivoire ${ }^{a}$

\begin{tabular}{lll}
\hline Indication & $\begin{array}{l}\text { Specific parts of } \\
\text { the plant }\end{array}$ & Preparation and administration \\
\hline Hemorrhoids & Leaves & $\begin{array}{l}\text { The leaves were boiled in water, and the decoction was consumed; part of the decoction was } \\
\text { mixed in shea butter and applied locally to hemorrhoids }\end{array}$ \\
Sinus disease & Leaves & A vapor bath was inhaled once a day for 3 days \\
Menstrual troubles & Leaves & The leaves were boiled in water, and the decoction was consumed 2 times a day for 2 months \\
Diarrhea & Leaves & The leaves were boiled in water, and the decoction was consumed 3 times a day for 3 days \\
Healing scars & Leaves & The pounded fresh leaves were applied as an ointment or rubbed on the scars \\
Febrifuge agent & Leaves & The leaves were boiled in water, and the decoction was consumed 2 times a day for 1 week \\
Vermifuge agent & Leaves & The leaves were boiled in water, and the decoction was consumed 2 times a day for 1 week \\
Scrofulous infection & Leaves and bark & $\begin{array}{l}\text { The pounded or crashed fresh leaves and barks were applied or rubbed on skin infections until } \\
\text { cured. }\end{array}$
\end{tabular}

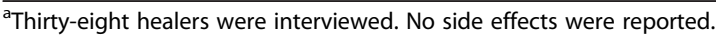

type II arabinogalactan (Table 2). Thus, it appears that the relative amount of type II arabinogalactan in parent fraction CSP-AU was too dilute to be detected by the Yariv reagent and that it became concentrated enough to be detected in the high-molecular weight sub-fraction CSP-AU1 after chromatography.

Sugar composition analysis revealed that the polysaccharides from C. splendens consisted primarily of galacturonic and glucuronic acids, arabinose, galactose, rhamnose, glucose, and mannose residues (Table 3$)$. Small $(<2 \%)$ amounts of fucose, xylose, and glucosamine residues were also detected in the fractions. In all fractions studied, arabinose and galactose were the major monosaccharides found, supporting that arabinogalactans are the primary macromolecules. Monosaccharide content in fractions bound and unbound to Diaion HP-20 resin differed by several fold for galacturonic acid, glucose, mannose, and glucosamine residues (Table 3). Analysis of the content of methoxyl groups in the fractions showed that both Diaion-bound fractions CSP-AB and CSP-NB had a high degree of methyl esterification of the uronic acid residues when compared to the Diaion-unbound fractions (Table 2).

The acidic fractions were enriched with polyphenols (up 9.5\%), whereas the neutral, relatively high molecular weight fractions (CSP-NB, CSP-NU, and CSP-NU1) had minimal amounts of polyphenols $(<1 \%)$.

\section{Effects of the Clerodendrum polysaccharide fractions on macrophage NO production}

To characterize effect of $C$. splendens polysaccharide fractions in a macrophage cell model, we first evaluated their effects on NO production by murine J774.A1 macrophages. The Diaion-bound neutral fraction CSP-NB and low-molecular weight sub-fractions CSP-AU2 and CSPNU2 were inactive or had low activity for induction of macrophage NO production. In contrast, all other fractions were highly active and stimulated levels of macrophage NO production that were comparable to those induced by LPS (Figure 1).

Table 2 Biochemical properties of $C$. splendens polysaccharide fractions

\begin{tabular}{|c|c|c|c|c|c|c|c|}
\hline \multicolumn{3}{|c|}{ Fractionation step \& Fraction name } & \multirow{2}{*}{$\begin{array}{l}\text { M.W. } \\
\text { (kDa) }\end{array}$} & \multirow{2}{*}{$\begin{array}{c}\text { Type II } \\
\text { Arabino- } \\
\text { galactan }\end{array}$} & \multirow{2}{*}{$\begin{array}{l}\text { Polyphenol } \\
\text { content (\%) }\end{array}$} & \multirow{2}{*}{$\begin{array}{l}\text { Methoxyl } \\
\text { content } \\
\text { (Mol \%) }\end{array}$} & \multirow{2}{*}{$\begin{array}{l}\text { DM } \\
(\%)^{\mathrm{a}}\end{array}$} \\
\hline DEAE cellulose & Diaion HP-20 & Sepharose 6B & & & & & \\
\hline \multirow[t]{4}{*}{ CSP-A } & CSP-AB & - & 13.2 & Negative & $9.3 \pm 0.29$ & $1.0 \pm 0.04$ & 81 \\
\hline & CSP-AU & - & 24.5 & Negative & $8.8 \pm 0.25$ & $0.9 \pm 0.04$ & 16 \\
\hline & & CSP-AU1 & 38.5 & Positive & $7.6 \pm 0.22$ & $0.9 \pm 0.04$ & 30 \\
\hline & & CSP-AU2 & 8.6 & Negative & $8.1 \pm 0.14$ & $1.3 \pm 0.03$ & N.D. \\
\hline \multirow[t]{4}{*}{ CSP-N } & CSP-NB & - & 12.0 & Negative & $0.9 \pm 0.03$ & $1.1 \pm 0.01$ & 67 \\
\hline & CSP-NU & - & 21.7 & Positive & $0.5 \pm 0.01$ & $1.0 \pm 0.02$ & 32 \\
\hline & & CSP-NU1 & 60.6 & Positive & $0.2 \pm 0.02$ & N.D. & N.D. \\
\hline & & CSP-NU2 & 5.5 & Negative & $6.5 \pm 0.14$ & N.D. & N.D. \\
\hline
\end{tabular}

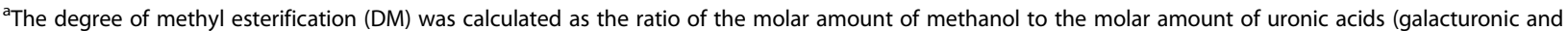
glucuronic acids) and is expressed as \%. N.D. not determined. 
Table 3 Sugar composition of polysaccharide fractions isolated from C. splendens ${ }^{a}$

\begin{tabular}{ccccccc}
\hline Monosaccharide & $\begin{array}{c}\text { CSP- } \\
\text { AU }\end{array}$ & $\begin{array}{c}\text { CSP- } \\
\text { AU1 }\end{array}$ & $\begin{array}{c}\text { CSP- } \\
\text { AB } \\
\text { Mol \% }\end{array}$ & $\begin{array}{c}\text { CSP- } \\
\text { NU }\end{array}$ & $\begin{array}{c}\text { CSP- } \\
\text { NU1 }\end{array}$ & $\begin{array}{c}\text { CSP- } \\
\text { NB }\end{array}$ \\
\hline Galacturonic Acid & 19.6 & 11.0 & 2.8 & 12.3 & 8.8 & 6.3 \\
Arabinose & 18.1 & 17.1 & 22.6 & 18.1 & 17.3 & 23.7 \\
Galactose & 17.1 & 27.0 & 19.1 & 31.7 & 37.7 & 26.5 \\
Rhamnose & 14.0 & 11.1 & 15.5 & 3.1 & 3.2 & 4.1 \\
Glucose & 9.6 & 11.1 & 15.7 & 5.0 & 4.8 & 15.0 \\
Glucuronic Acid & 3.9 & 3.8 & 3.7 & 1.6 & 1.6 & 1.2 \\
Mannose & 2.9 & 5.6 & 13.5 & 7.6 & 5.2 & 9.5 \\
Fucose & 1.8 & 1.6 & 1.7 & 1.0 & 1.3 & 0.9 \\
Xylose & 0.6 & 1.2 & 0.7 & 2.0 & 1.3 & 1.3 \\
Glucosamine & 1.3 & 1.3 & 3.5 & 0.5 & 0 & 0.7 \\
Lyxose & 0 & 0 & 0 & 0 & 0 & 0 \\
\hline
\end{tabular}

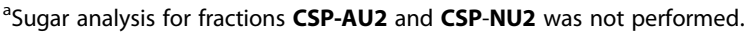

\section{Effects of Clerodendrum polysaccharide fractions on cytokine production in cell cultures}

The basic mechanism of the immunostimulatory effects of botanical polysaccharides is thought to occur via macrophage stimulation (reviewed in [22]). Thus, we analyzed effects of C. splendens polysaccharide fractions on TNF production by murine J774.A1 macrophages, human monocytic MonoMac-6 cells, and human primary PBMCs. We tested samples in murine and human cell lines, as well as primary human cells because we often see differences in macrophage responses between species. Thus, it is important to confirm similar responses in murine phagocytes when considering future in vivo studies using a murine model. In addition, confirmation of cell line responses in primary cells is important to confirm cell line responses are also relevant to primary cells. We found that Diaionbound fractions CSP-NB and CSP-AB and the acidic low-molecular weight sub-fraction CSP-AU2 had relatively low activity in J774.A1 and MonoMac-6 cell cultures. All other fractions induced high levels of TNF production by these cell lines, as well as by PBMCs, and the levels of TNF produced were comparable to those induced by LPS (Figure 2). Effects of Clerodendrum polysaccharide fractions on IL-6 production were also analyzed in murine J774.A1 macrophages. Again we found that the low-molecular weight sub-fraction CSP-AU2 and both Diaion-bound fractions CSP-NB and CSP-AB had low activity, whereas all other $C$. splendens polysaccharide fractions effectively stimulated IL-6 production (Figure 3).

Similarly, all C. splendens polysaccharide fractions except the Diaion-bound polysaccharide fractions CSP-NB and CSP-AB and the low-molecular weight sub-fraction CSP-AU2, induced high levels of GM-CSF production by MonoMac-6 cells and PBMCs (Figure 4). Note, however, that even high concentrations of LPS (up to 10 $\mu \mathrm{g} / \mathrm{ml}$ ) were unable to stimulate GM-CSF production by human PBMCs. In contrast, Con A dose-dependently stimulated production of this cytokine by PBMCs over a concentration range of 1 to $20 \mu \mathrm{g} / \mathrm{ml}$ (Figure 5).
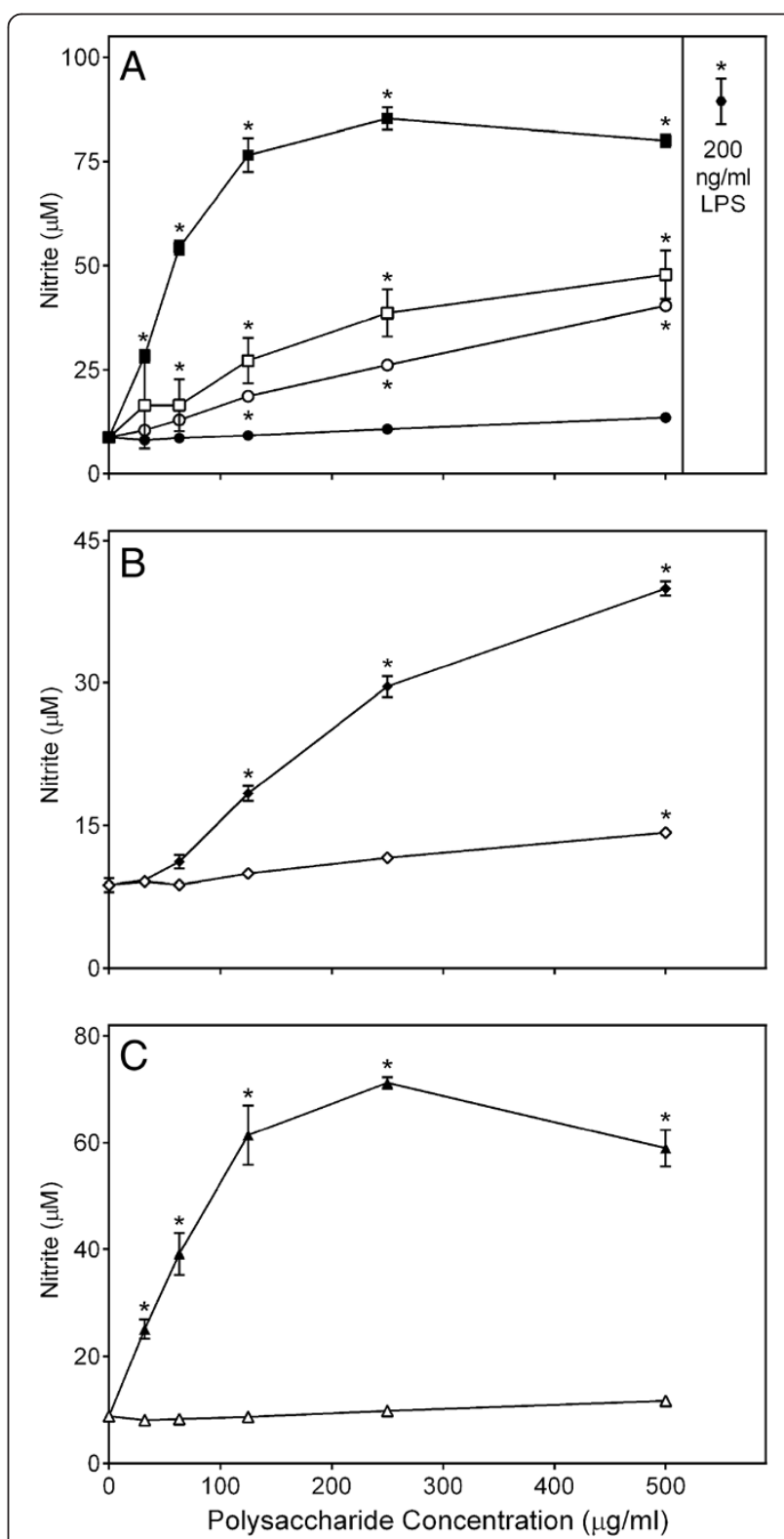

Figure 1 Effect of Clerodendrum polysaccharide fractions on murine macrophage nitric oxide production. Murine J774.A1 macrophages were incubated for $24 \mathrm{hr}$ with the indicated concentrations

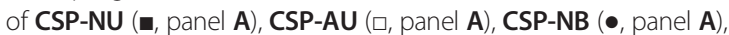
CSP-AB (O, panel A), CSP-AU1 $(\downarrow$, panel B), CSP-AU2 $(\diamond$, panel B), CSP-NU1 ( $\mathbf{A}$, panel C), CSP-NU2 $(\boldsymbol{\Delta}$, panel C), or $200 \mathrm{ng} / \mathrm{ml}$ LPS , panel $\mathbf{A})$. Values are the mean \pm S.D. of triplicate samples from one experiment, which is representative of two independent experiments. Statistically significant differences $\left({ }^{*} p<0.05\right)$ between PBS-treated cells and cells treated with polysaccharide fractions or LPS are indicated. 


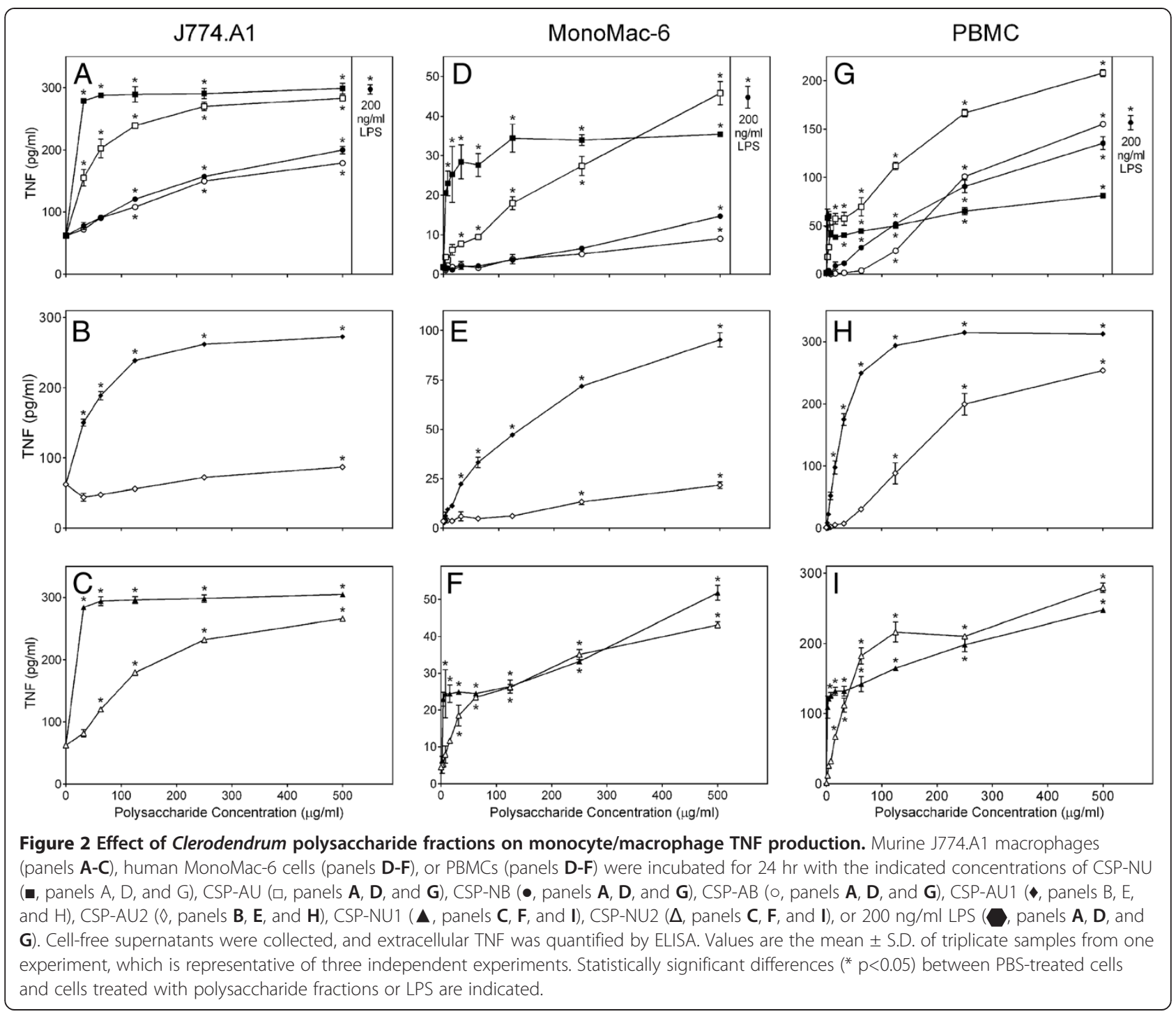

To determine if polysaccharides from different plant sources could stimulate similar levels of GM-CSF production, we evaluated the effect of polysaccharide fractions from several different plants. These previously characterized polysaccharide fractions included fraction A-I from Artemisia tripartite [23], fraction T-I from Tanacetum vulgarie [24], and fraction C-I from Opuntia polyacanta [25]. Interestingly, none of these polysaccharide fractions induced GM-CSF production by human PBMCs (data not shown). On the other hand, our previous studies showed that these polysaccharides could potently activate production of various other cytokines, such as TNF and IL-6, in phagocytes [23-25].

Because CSP-AU1 was one of the most potent fractions for activation of TNF, IL-6, and GM-CSF production, we next determined whether this sub-fraction could modulate production of other cytokines by PBMCs using a multicytokine ELISA semiquantitative array. Among the 12 cytokines analyzed, six were consistently induced in PBMCs (>4-fold) by $250 \mu \mathrm{g} / \mathrm{ml}$ of CSP-AU1, as compared with control (HBSS-treated) cells. These included IL-1 $\alpha$ $(\mathrm{FI}=6.0), \mathrm{IL}-1 \beta(\mathrm{FI}=32.6), \mathrm{IL}-6 \quad(\mathrm{FI}=42.4), \mathrm{IL}-10 \quad(\mathrm{FI}=$ 4.6), TNF (FI = 22.7), and GM-CSF ( FI= 20.9) (Figure 6). IL-8 production was inconclusive because of its high background production by PBMCs (data not shown), a problem which has also been documented previously (e.g., [26]). Thus, these results confirmed activation of IL-6, TNF, and GM-CSF production by CSP-AU1, but also that this polysaccharide fraction induced IL- $1 \alpha$, IL-1 $\beta$, and IL10 production.

\section{Effect of the Clerodendrum polysaccharide fractions on AP-1/NF-KB activity}

To evaluate signaling pathways involved in the immunomodulatory activity of $C$. splendens polysaccharide fractions, we utilized a transcription factor-based bioassay for 

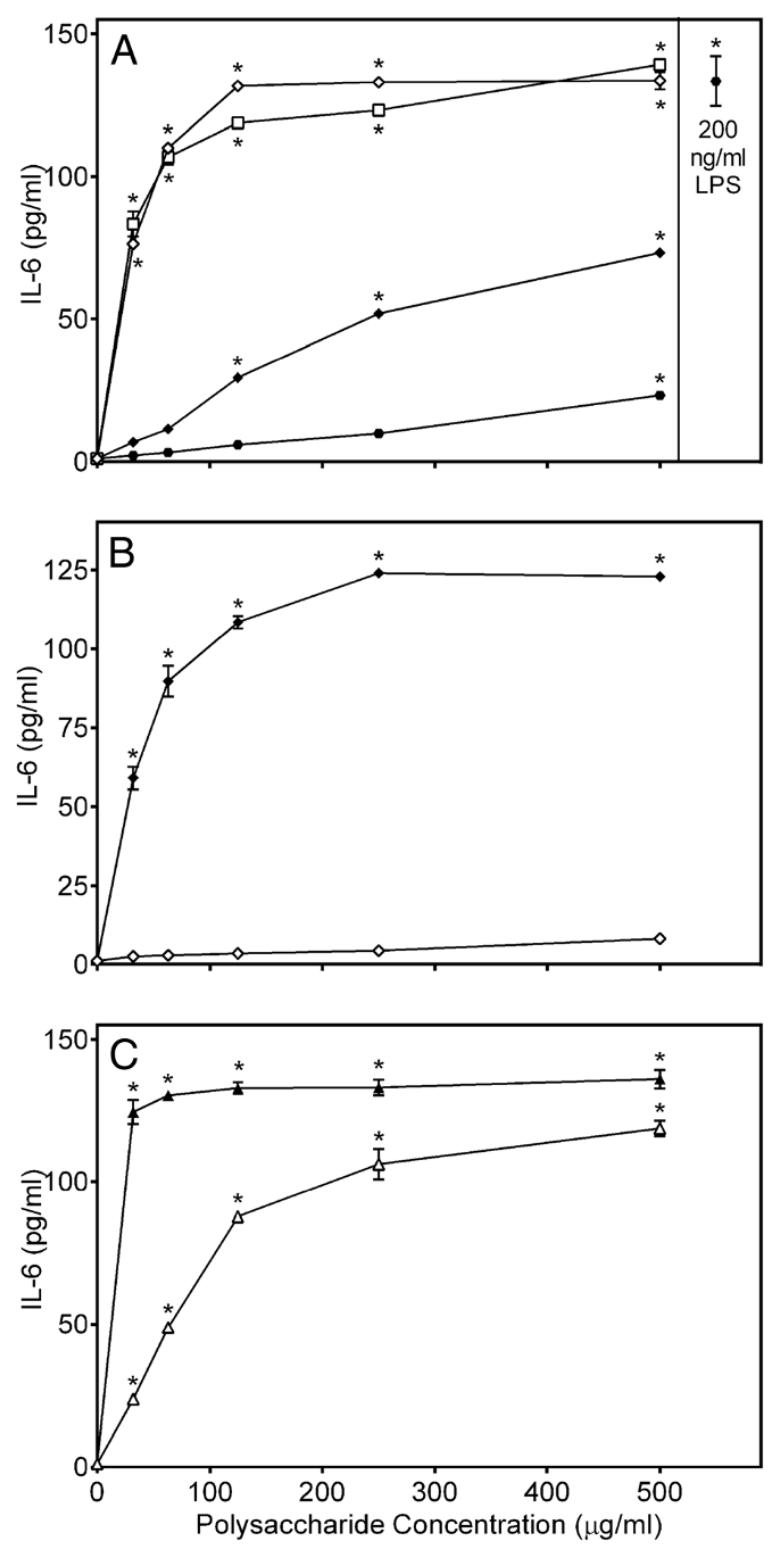

Figure 3 Effect of Clerodendrum polysaccharide fractions on macrophage IL-6 production. Murine J774.A1 macrophages were incubated for $24 \mathrm{hr}$ with the indicated concentrations of CSP-NU

$(\square$, panel A), CSP-AU ( $\square$, panel A), CSP-NB $(\bullet$, panel A), CSP-AB $(0$, panel A), CSP-AU1 $($, panel B), CSP-AU2 $(\nabla$, panel B), CSP-NU1

(ム, panel C), CSP-NU2 ( $\Delta$, panel C), or $200 \mathrm{ng} / \mathrm{ml}$ LPS ( panel A) Cell-free supernatants were collected, and extracellular IL-6 was quantified by ELISA. Values are the mean \pm S.D. of triplicate samples from one experiment, which is representative of three independent experiments. Statistically significant differences $\left({ }^{*} p<0.05\right)$ between PBS-treated cells and cells treated with polysaccharide fractions or LPS are indicated.

AP-1/NF- $k$ B activation in human THP-1Blue monocytes. Similar to activity of the fractions in our analysis of cytokine production, both Diaion-bound fractions CSP-NB and CSP-AB and the low-molecular weight sub-fraction CSP-AU2 were inactive or had low activity for inducing
AP-1/NF-kB. In contrast, CSP-NU and both highmolecular weight sub-fractions CSP-AU1 and CSP-NU1 dose-dependently induced AP-1/NF- $\mathrm{B}$ transcriptional activity, as determined by monitoring alkaline phosphatase release (Figure 7).

\section{Effect of Clerodendrum polysaccharide fractions on cell viability}

Although our functional assays suggested that the polysaccharides extracted from C. splendens were relatively nontoxic, we evaluated their potential cytotoxic effects to determine if the results might be influenced by background toxicity. Using a cytotoxicity assay, we determined that none of the polysaccharides significantly affected viability of human PBMCs, THP-1Blue, or MonoMac-6 cells over the concentration range of $10-250 \mu \mathrm{g} / \mathrm{ml}$ polysaccharides, verifying that these polysaccharides were not toxic to these cells (data not shown).

\section{Effect of CSP-AU1 on TLR4-dependent pathway and phosphorylation of MAPK family}

LPS from the photosynthetic bacterium Rhodobacter sphaeroides (LPS-RS) is a potent TLR4 antagonist, and the primary mechanism of the antagonism consists of direct competition with LPS from $E$. coli or other pathogenic bacteria for the same binding site on myeloid differentiation protein 2 (MD-2), an essential co-receptor in the LPS/TLR4 signaling pathway [27]. As shown in Figure 8, LPS-RS alone had a negligible effect on TNF production in PBMCs and MonoMac-6 cells. However, LPS-RS $(2 \mu \mathrm{g} / \mathrm{ml})$ completely inhibited TNF secretion by PBMCs activated with $250 \mu \mathrm{g} / \mathrm{ml}$ of CSP-AU1 or 200 $\mathrm{ng} / \mathrm{ml}$ of LPS (Figure $8 \mathrm{~A}$ ). The effect of this TLR4 antagonist on TNF secretion by MonoMac-6 cells was fairly similar; 10 and $0.2 \mu \mathrm{g} / \mathrm{ml}$ of LPS-RS completely inhibited TNF secretion by MonoMac- 6 cells induced by $250 \mu \mathrm{g} / \mathrm{ml}$ of CSP-AU1 and $200 \mathrm{ng} / \mathrm{ml}$ of LPS, respectively (Figure 8B). It should be noted that LPS-RS was unable to inhibit TNF secretion by PBMCs activated with 200 nM PMA (data not shown).

Stimulation of cytokine production by monocyte/macrophages depends on multi-signaling pathways, including MAPKs [28]. To simultaneously evaluate effects of fraction AP-AU1 on the activation status of all three major MAPKs, extracellular-signal regulated kinases (ERK1/ ERK2), c-Jun N-terminal kinases (JNK 1-3), different p38 MAPK isoforms $(\alpha, \beta, \delta$, and $\gamma)$ and other intracellular kinases, such as MSK2, mTOR, CREB, HSP27, p53, Akt, glycogen synthase kinase (GSK-3), p90 ribosomal S6 kinase (RSK)1/2, MAP kinase kinases (MKK2, MKK3, and MKK6), and p70 S6 kinase 1 (p70S6K1) in hPBMCs, we utilized a human phospho-MAPK array (Proteome Profiler $^{\mathrm{rm}}$; R\&D Systems), which monitors the phosphorylation of multiple intracellular kinases. Treatment with 

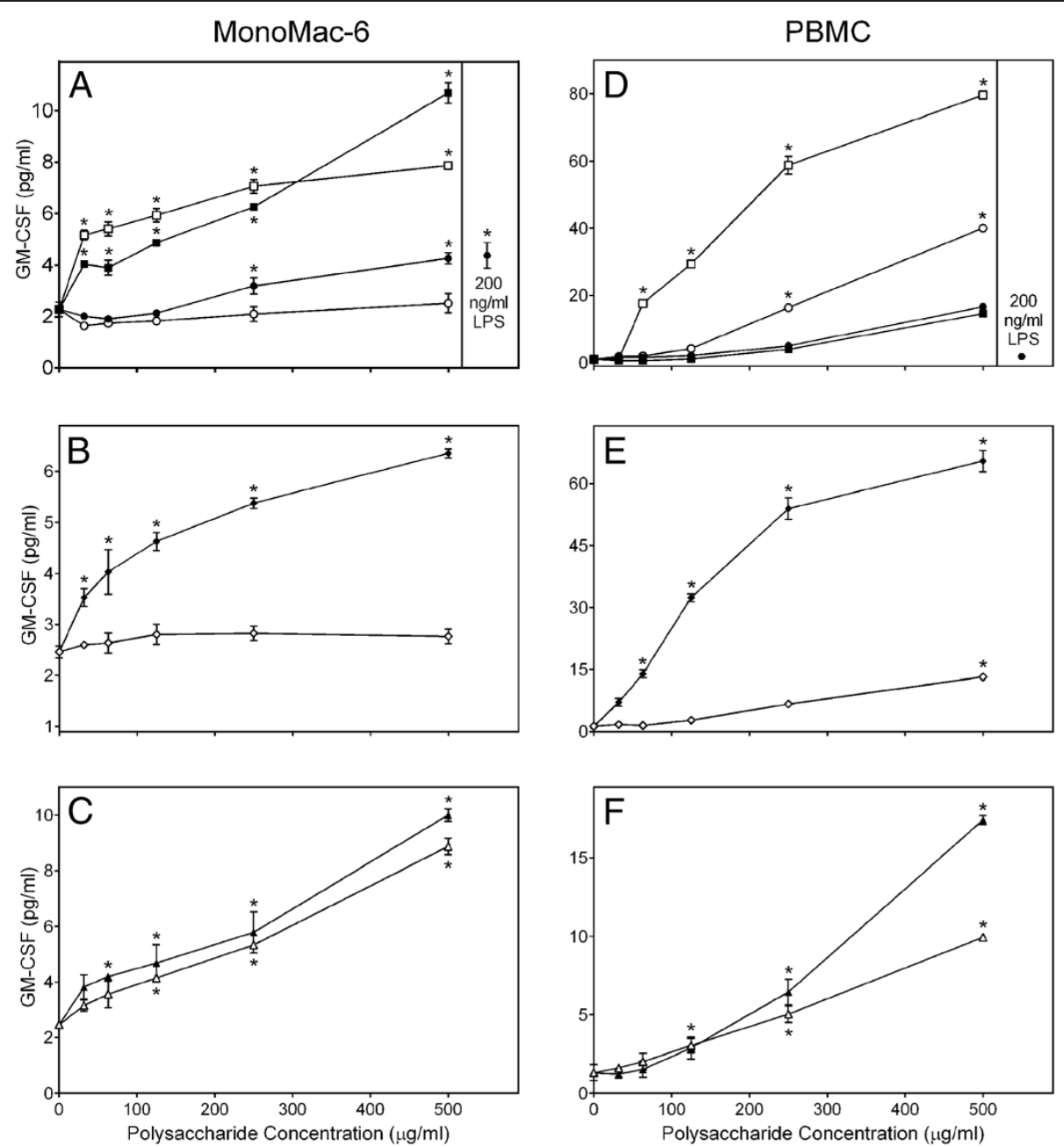

Figure 4 Effect of Clerodendrum polysaccharide fractions on monocyte/macrophage GM-CSF production. Human MonoMac-6 cells (panels $\mathbf{A}-\mathbf{C}$ ) or PBMCs (panels D-F) were incubated for $24 \mathrm{hr}$ with the indicated concentrations of CSP-NU ( $\mathbf{m}$, panels $\mathbf{A}$ and $\mathbf{D})$, CSP-AU $(\square$, panels $\mathbf{A}$ and $\mathbf{D}), \mathbf{C S P}-\mathbf{N B}(\bullet$, panels $\mathbf{A}$ and $\mathbf{D}), \mathbf{C S P}-\mathbf{A B}(0$, panels $\mathbf{A}$ and $\mathbf{D})$, CSP-AU1 $(\bullet$, panels B and E), CSP-AU2 $(\boldsymbol{\nabla}$, panels $\mathbf{B}$ and $\mathbf{E})$, CSP-NU1 ( $\mathbf{\Delta}$, panels $\mathbf{C}$ and $\mathbf{F}), \mathbf{C S P}-\mathbf{N U 2}(\Delta$, panels $\mathbf{C}$ and $\mathbf{F})$, or $200 \mathrm{ng} / \mathrm{ml} \mathrm{LPS}(\mathbf{D}$, panels $\mathbf{A}$ and $\mathbf{D})$. Cell-free supernatants were collected, and extracellular TNF was quantified by ELISA. Values are the mean \pm S.D. of triplicate samples from one experiment, which is representative of three independent experiments. Statistically significant differences (* $\mathrm{p}<0.05)$ between PBS-treated cells and cells treated with polysaccharide fractions or LPS are indicated.

CSP-AU1 specifically increased ( $>2$-fold) phosphorylation Akt2 $\left[\mathrm{Ser}^{474}\right.$; fold increase $\left.(\mathrm{FI})=3.2\right]$, Akt3 $\left(\mathrm{Ser}^{472}, \mathrm{FI}=4.7\right)$, GSK-3 $\alpha / \beta(\mathrm{FI}=2.1), \mathrm{p} 38 \beta\left(\mathrm{Thr}^{221} / \mathrm{Tyr}^{223}, \mathrm{FI}=2.2\right), \mathrm{p} 38 \delta$ $\left(\mathrm{Thr}^{180 / \mathrm{Tyr} 182} ; \mathrm{FI}=3.6\right), \mathrm{p} 38 \gamma \quad\left(\mathrm{Thr}^{183} / \mathrm{Tyr}^{185} ; \mathrm{FI}=2.4\right)$, p70S6K1 $\left(\mathrm{Thr}^{421} / \mathrm{Ser}^{424} ; \mathrm{FI}=4.5\right)$, RSK2 $\left(\mathrm{Ser}^{386} ; \mathrm{FI}=3.0\right)$, and mTOR $\left(\mathrm{Ser}^{2448} ; \mathrm{FI}=2.5\right)$ in human PBMCs (Figure 9).

\section{Effect of CSP-AU1 on cytokine concentration in serum}

Both high activity (CSP-AU1 and CSP-NU1) and low activity (CSP-AU2) fractions were evaluated for their ability to modulate production of different cytokines in serum using a multi-cytokine semiquantitative ELISA array. We found that the profiles of cytokine-stimulatory activity of CSP-AU1 and CSP-NU1 were comparable to that of LPS (single dose of $500 \mu \mathrm{g} / \mathrm{kg}$ ). Among the 13 cytokines analyzed, six were consistently increased in serum ( $>2$-fold) by a single dose of CSP-AU1 or CSP-NU1 $(250 \mathrm{mg} / \mathrm{kg})$ at $2 \mathrm{hr}$, as compared with control (PBS-treated) mice. These included IL-10 (FI= 2.2 and 3.7), IL-6 ( $\mathrm{FI}=16.6$ and 29.3), TNF (FI $=2.4$ and 4.1), monocyte chemoattractant protein$1(\mathrm{MCP}-1)(\mathrm{FI}=11.2$ and 6.0), MIP-1 $\alpha / \mathrm{CCL} 3(\mathrm{FI}=6.9$ and 2.5 ), and MIP-1ß/CCL4 (FI $=21.8$ and 20.5 , by subfractions CSP-AU1 and CSP-NU1, respectively) (Figure 10). It should be noted that only two cytokines MCP-1 (FI= 5.2) and MIP-1 $\beta / C C L 4$ ( $\mathrm{FI}=4.6)$ were significantly increased in serum ( $>2$-fold) by injection of the low molecular weight sub-fraction CSP-AU2, which correlated with its low activity in our in vitro assays.

Because CSP-AU1 was the most abundant fraction among the isolated Clerodendrum polysaccharide fractions 


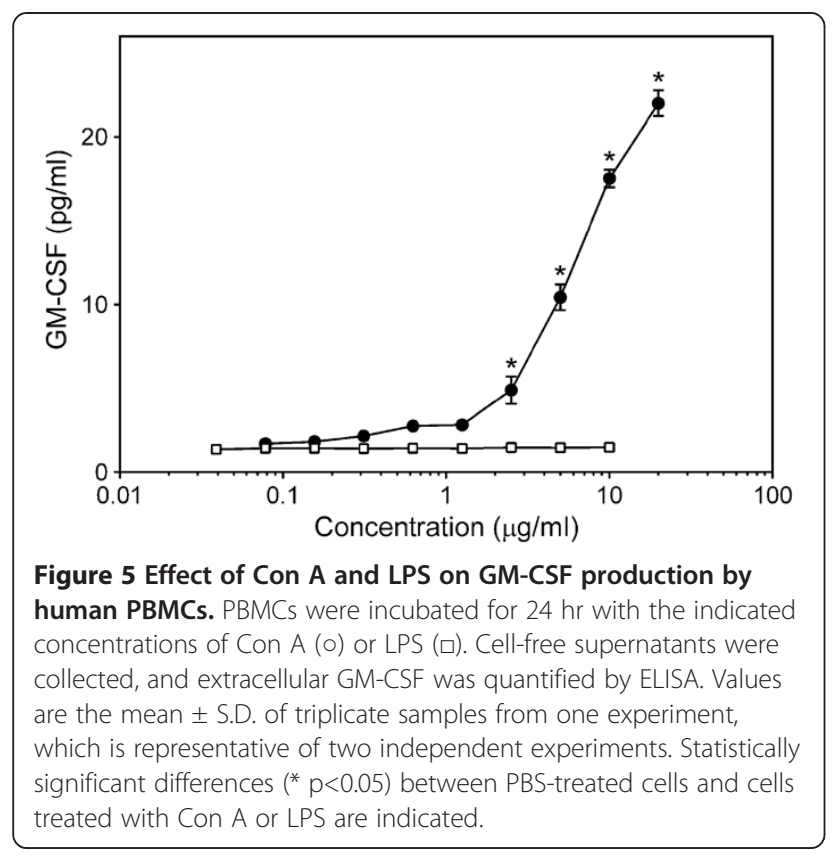

(its yield was $\sim 5$ times larger than yield of CSP-NU1; data not shown), we used CSP-AU1 for subsequent in vivo studies. After i.p. administration of CSP-AU1 (single injection in dose of $250 \mathrm{mg} / \mathrm{kg}$ ), a rapid rise in serum TNF concentration was observed, peaking at $\sim 2 \mathrm{hr}$ (Figure 10, Inset $A$ ). When mice were treated with different doses of CSPAU1, a dose-dependent increase in serum TNF concentration was found at $2 \mathrm{hr}$ (Figure 10, Inset B).

\section{Effect of CSP-AU1 on EAE}

Because CSP-AU1 had potent TLR4-dependent immunomodulatory effects via MD-2, we hypothesized that this polysaccharide might have a clinically beneficial effect on autoimmune diseases. Indeed, chronic stimulation of the innate immune system via TLR4 leads to the induction of immunosuppression [29], and several plant polysaccharide with immunomodulatory activities were recently found to have therapeutic effects in several autoimmune disease models, including EAE [30-34]. In multiple sclerosis and its animal model EAE, myelin auto-reactive T cells and macrophages migrate into the central nervous system via a broken blood-brain barrier. The inflammatory cascade stimulated by these cells ultimately leads to neuroinflammatory injury and myelin sheath destruction [35]. To test whether CSPAU1 could down-regulate inflammation in EAE, mice were treated daily (starting on day 4 after immunization with $\mathrm{MOG}_{35-55}$ peptide) with $50 \mathrm{mg} / \mathrm{kg}$ of CSP-AU1. Notably, we found that CSP-AU1 effectively delayed onset of EAE by 2 days as well as decreasing disease severity. In the PBStreated group, EAE developed at day 10 after challenge and reached a maximal clinical score at day 14 . In contrast, the polysaccharide-treated group had a delayed onset of symptoms (day 11) and far less severe disease, reaching a maximal clinical score at day 17 (insignificant difference with PBS-treated group at day 17, p>0.05) (Figure 11).

To understand the mechanisms responsible for reduced EAE disease in CSP-AU1-treated mice, mononuclear cells from spleens and head and neck LNs were isolated from CSP-AU1- and PBS-treated EAE mice on day 17 after immunization and cultured 4 days with the $\mathrm{MOG}_{35-55}$ peptide. As shown in Figure 12, high levels of IL-13, IL-17, GM-CSF, INF- $\gamma$, and TNF were produced in LN cells from PBS-treated EAE mice, while secretion of all of these cytokines was significantly decreased in cultures of these cells from CSP-AU1-treated EAE mice. The levels of anti-inflammatory cytokines IL-4 and IL-10 were similar in the LN supernatants from CSP-AU1treated and control animals. For splenic cells, decreased IL-4, IL-10, IL-17, GM-CSF, and IFN- $\gamma$ levels were found in CSP-AU1-treated mice. On the other hand, TGF- $\beta$ was increased in both splenocytes and LN cells from CSP-AU1-treated EAE mice relative to PBS control mice (Figure 12).

\section{Discussion}

Historically, C. splendens has been used in African folk medicine for treating a number of diseases and medical conditions. However, despite the widespread traditional use of $C$. splendens in tropical countries, little is known regarding the active components responsible for its therapeutic

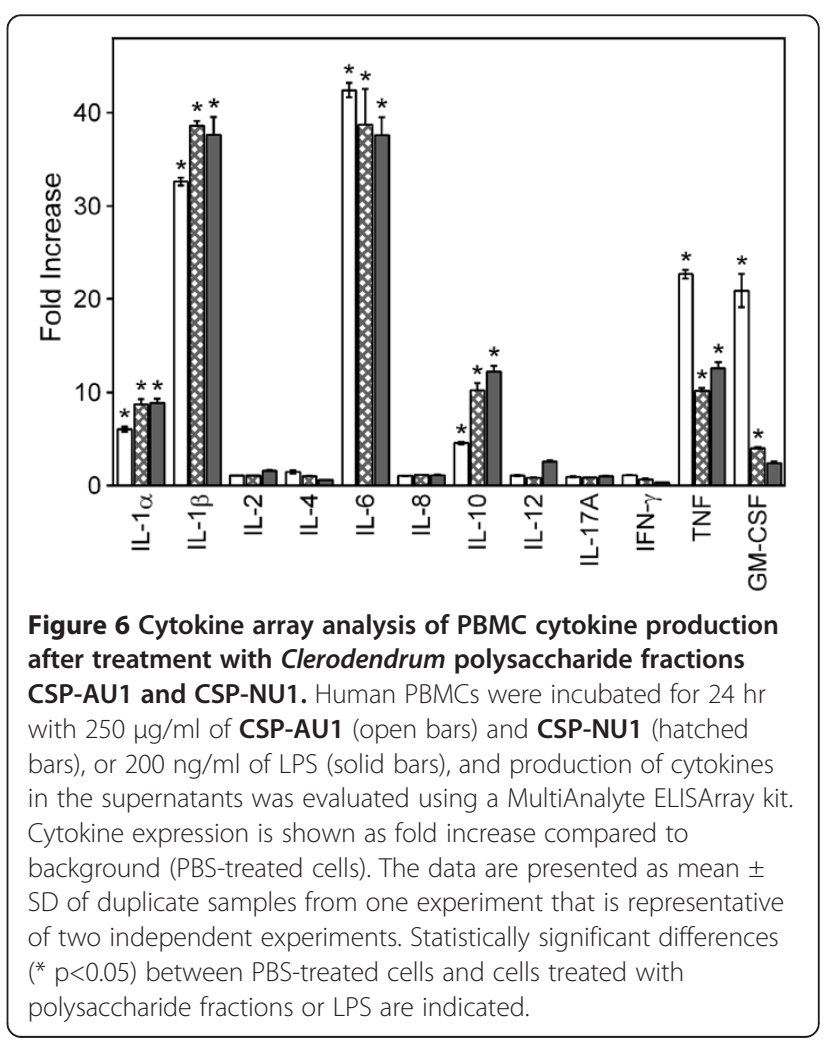




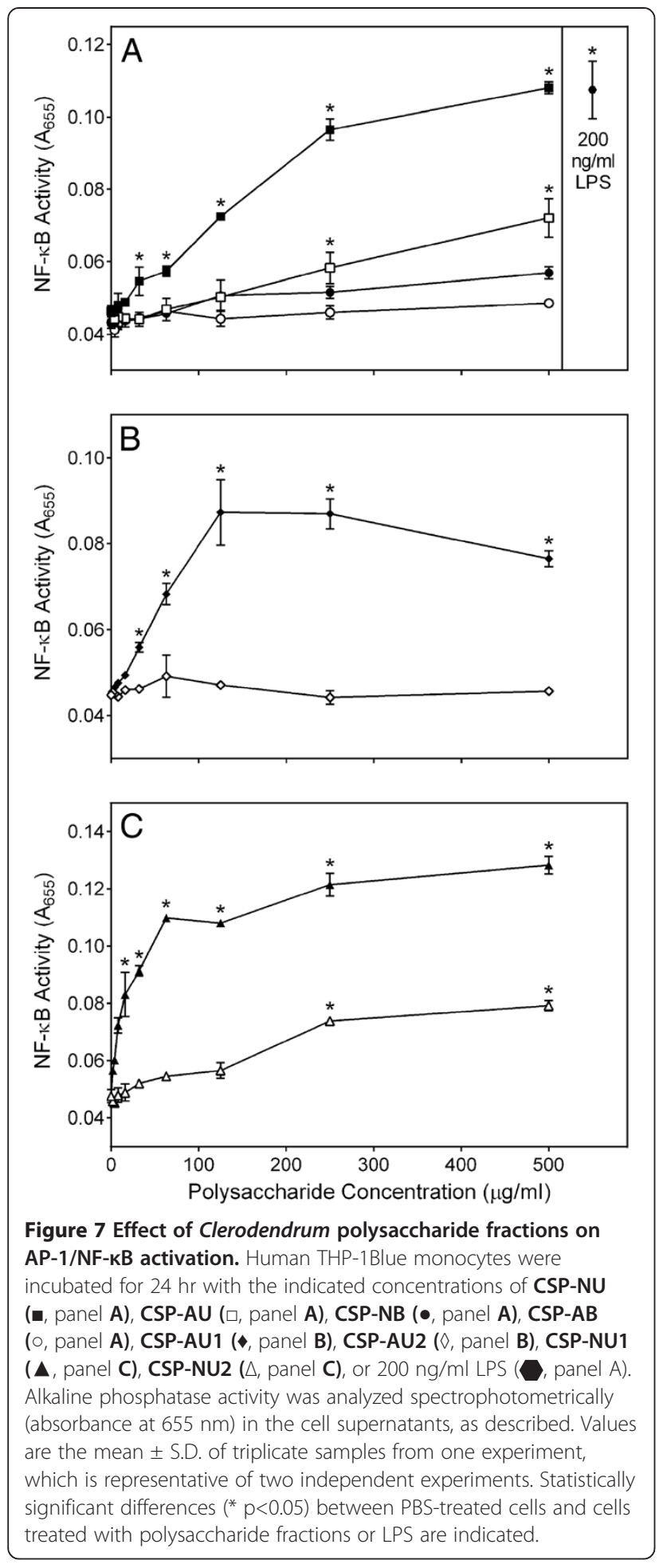

properties. Previously, antipyretic and anti-inflammatory effects of methanolic extracts from $C$. splendens have been described [11], whereas the immunomodulatory activities of high-molecular weight polysaccharide fractions from this plant are unknown. In the present work, we provide evidence demonstrating that C. splendens polysaccharides have potent immunomodulatory properties in vitro and in vivo and suggest that this may contribute, at least in part, to the therapeutic potential of $C$. splendens-derived medicines.

Our ethnobotanical survey and literature review indicate that a decoction in water of the leaves is the mode of extraction most commonly used to prepare remedies from $C$. splendens in African folk medicine. Based on this observation, we isolated eight polysaccharide fractions from the hot-water extract of $C$. splendens leaves and provided initial structural and pharmacological characterization. Average molecular weights of the fractions were in the range of 5.5 to $60.6 \mathrm{kDa}$. We found that the high-molecular weight subfractions CSP-AU1 (mol. weight $38.5 \mathrm{kDa}$ ) and CSP-NU1 (mol. weight $60.6 \mathrm{kDa}$ ) were quite potent in biological tests, whereas the low-molecular weight sub-fraction CSP-AU2 was inactive or minimally active in the same assays. Indeed, sub-fractions CSP-AU1 and CSP-NU1 contained potent immunomodulatory activity, as demonstrated by their ability to induce NO production in macrophage J774.A1 cells and cytokines by monocyte/macrophages and human PBMCs. These cytokines included of IL-1 $\alpha$, IL-1 $\beta$, IL-6, TNF, IL-10, and GM-CSF. In addition, we found that CSPAU1 and CSP-NU1 induced increased levels of certain serum cytokines in vivo, including the anti-inflammatory cytokine IL-10 and pro-inflammatory cytokines IL-6, TNF, MCP-1, MIP- $1 \alpha$, and MIP- $1 \beta$. In contrast, the lowmolecular weight sub-fraction CSP-AU2 was minimally active in vivo (Figure 10).

A common feature of plant polysaccharides that modulate macrophage functions may be higher molecular weight, as we found previously that immunomodulatory activity positively correlated with increased molecular weight of various plant polysaccharides [23-25,36]. Although the immunologic effects of Clerodendrum polysaccharides following oral administration were not studied in the present work, numerous dietary polysaccharides do appear to elicit diverse immunomodulatory effects in various animal tissues, including the blood, gastrointestinal tract and spleen [37-42]. Note, however, that our recent studies suggest that nasal application of some plant polysaccharides may be even more effective than oral administration for stimulation of innate immunity [43]. In any case, further studies are now in progress to determine the therapeutic potential of Clerodendrum polysaccharide sub-fraction CSP-AU1 and its structural features conferring biological activity.

Active and inactive polysaccharide fractions contained polyphenols, which were present over a broad range. Polyphenols have been previously noted in polysaccharide fractions of various plants (e.g. [42,44]), and it has been reported that polysaccharides are able to bind to polyphenols by intermolecular interactions [45], changing the molecular conformation of carbohydrates. Therefore, the presence of polyphenols in polysaccharide fractions must be considered. However, activities of the fractions did not 

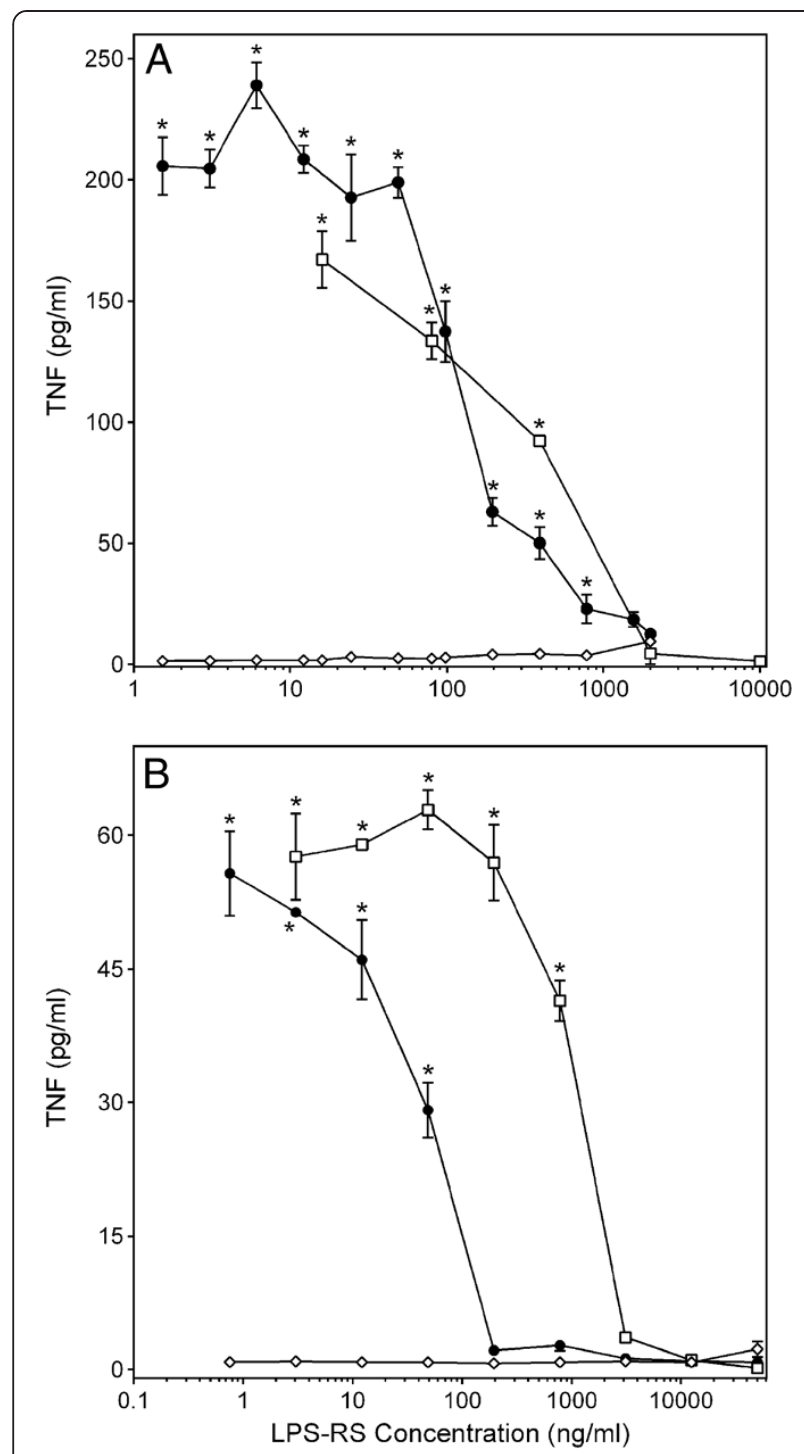

Figure 8 Effect of TLR4 antagonist LPS-RS on TNF production by monocyte/macrophages activated with Clerodendrum polysaccharide fraction CSP-AU1. Human PBMCs (Panel A) or MonoMac-6 cells (Panel B) were pretreated with indicated concentrations LPS-RS for $30 \mathrm{~min}$, followed by treatment with media (negative control, -), CSP-AU1 $(250 \mu \mathrm{g} / \mathrm{ml}$, o), or LPS (200 ng/ml, 口) for $24 \mathrm{hr}$, and extracellular TNF was quantified by ELISA. Values are the mean \pm S.D. of triplicate samples from one experiment, which is representative of three independent experiments. Statistically significant differences ( $\left.{ }^{*} p<0.05\right)$ between PBS-treated cells and cells treated with the indicated concentrations of LPS-RS plus fraction CSP-AU1 or LPS are indicated.

correlate with polyphenol content in our biological studies. Indeed, one of the most active fractions (CSP-AU1) contained a relatively high level of polyphenols (7.6\%), whereas other polyphenol-enriched fractions (CSP-AB, 9.3\% polyphenols; CSP-AU2, 8.8\% polyphenols) were inactive or had low activity in most biological assays. Finally, the highly active sub-fraction CSP-NU1 had the lowest polyphenol content $(0.2 \%)$.
We found that both of the Diaion-bound fractions, CSP$\mathrm{AB}$ and CSP-NB, generally were inactive or had low biological activity. Sugar analysis showed that these fractions contained much less galacturonic acid but more neutral sugars (glucose and mannose) than the Diaion-unbound fractions CSP-AU and CSP-AU. Moreover, analysis of the fractions using the Yariv reagent demonstrated that both CSP-AB and CSP-NB tested negative for the presence of type II arabinogalactan. Conversely, the most potent immunomodulatory properties were associated with the fractions that exhibited a positive reaction for type II arabinogalactan. Thus, native type II arabinogalactans could be the main structures responsible for immunomodulatory properties of the C. splendens-derived polysaccharides, although presence of type I arabinogalactan in the fractions could not be excluded. In any case, it appears that Diaion HP-20 resin could be used to enrich bioactive $C$. splendens polysaccharides by removing inactive material that bound to the resin [46]. Note, we also evaluated if the inactive Diaion-bound material might possibly have inhibitory activity by assessing its ability to inhibit LPS-induced cytokine production but found that this material was inactive, having no effect on LPS induced cytokine production (data not shown). Future chemical and physical analysis of these fractions will be necessary for characterization of Diaion-bound and unbound polysaccharide fractions and definition of the polysaccharide structures responsible for immunomodulatory activities.

Previously it was proposed that selective immunostimulatory and anti-inflammatory properties of citrus polysaccharides could be attributed to different degrees of methyl esterification [47-49]. In the present study, we found that the polysaccharide fraction with the most potent immunomodulatory activity (CSP-AU1) had a low

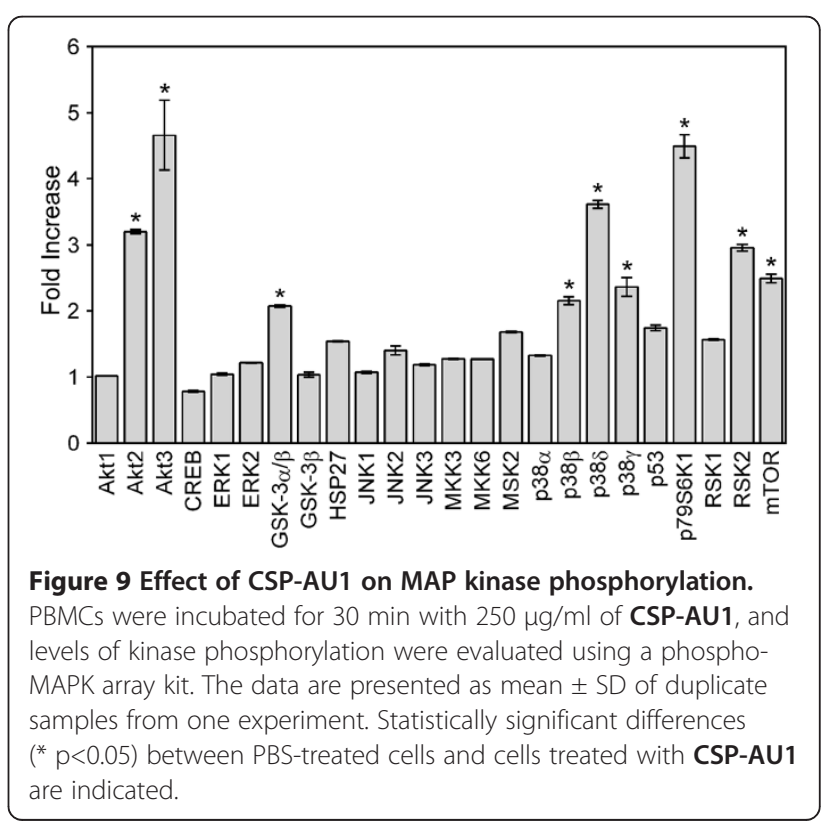




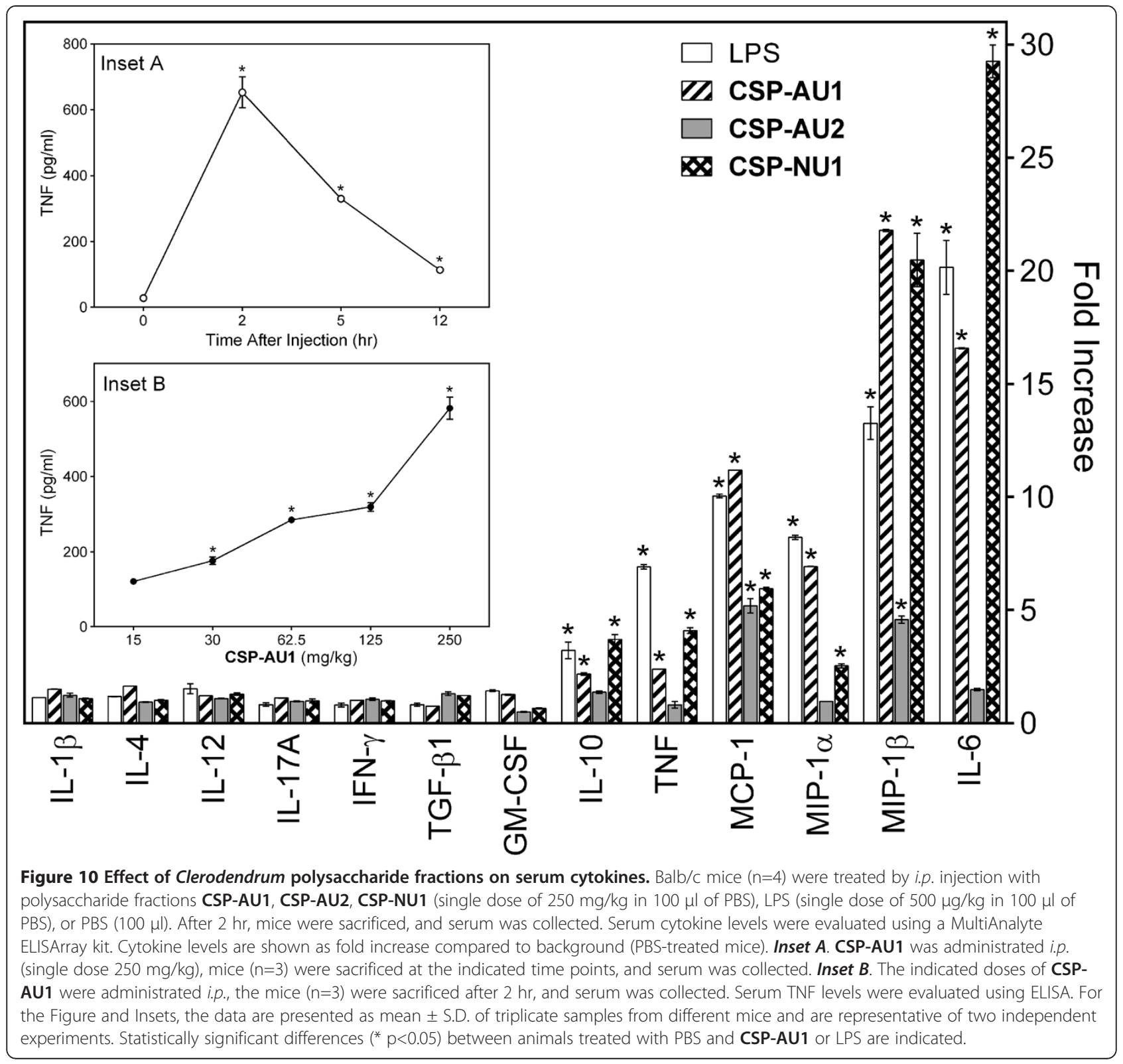

degree of methyl esterification of uronic acid residues. Thus, free carboxylic groups and associated electrical charge may enhance the bioavailability and binding potential of CSP-AU1 polysaccharides to different cell receptors.

Clerodendrum polysaccharides and recently characterized polysaccharides from Alchornea cordofolia [50] seem to be unique, as compared to LPS and many other plant polysaccharides, in their ability to induce GM-CSF production by MonoMac- 6 cells and PBMCs. Indeed, previously characterized polysaccharide fractions A-I from A. tripartite [23], T-I from T. vulgare [24], C-I from O. polyacanta [25], and even high concentrations of LPS (up to $10 \mu \mathrm{g} / \mathrm{ml}$ ) were unable to stimulate GM-
CSF production by human PBMCs, whereas CSP-AU, CSP-AU1, CSP-NU1, and CSP-NU2 all significantly induced production of this cytokine by MonoMac- 6 cells and PBMCs.

Because Con A stimulated GM-CSF production by human PBMCs (Figure 5), we considered whether the GMCSF-inducing activity of Clerodendrum polysaccharide fractions might correlate with hemagglutinating activity but found that the Clerodendrum polysaccharides, as well as polysaccharides isolated from A. cordofolia [50], had no hemagglutinating activity (up to $1 \mathrm{mg} / \mathrm{ml}$ ). On the other hand, we found that polysaccharide CP-AU isolated from Combretum racemosum had relatively high hemagglutinating activity but minimally stimulated GM- 


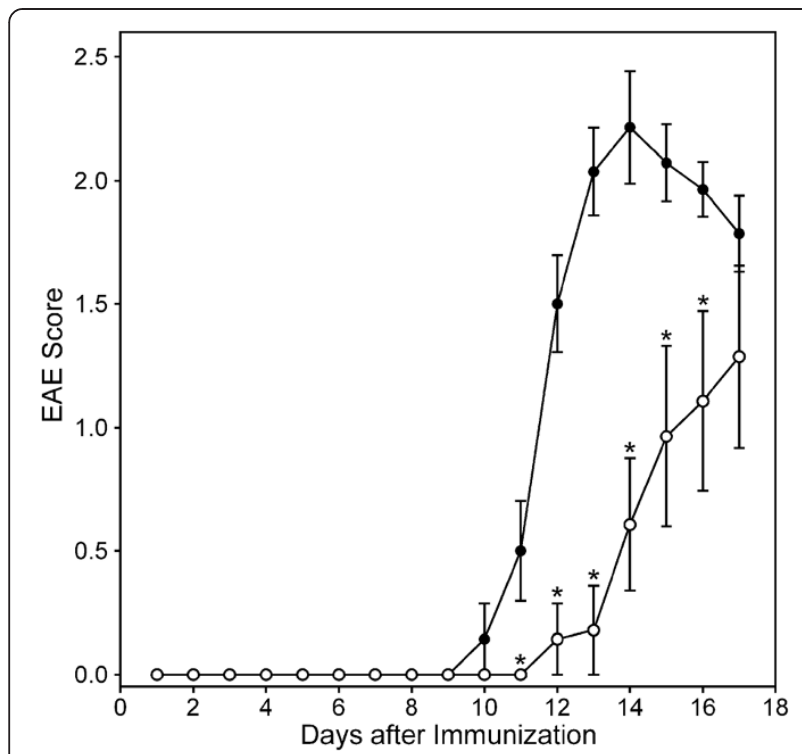

Figure 11 Effect of CSP-AU1 on EAE. C57BL/6 mice were treated i.p. daily with $50 \mathrm{mg} / \mathrm{kg}$ of CSP-AU1 (o) or PBS (•), starting on day 4 after immunization with $\mathrm{MOG}_{35-55}$ peptide. The average score of 14 mice per group is shown, and statistically significant differences (* $\mathrm{p}<0.05)$ between EAE mice treated with PBS or fraction CSP-AU1 are indicated. A representative experiment of two independent experiments is shown.

CSF production by human PBMCs and only at the highest tested concentration $(0.5 \mathrm{mg} / \mathrm{ml})$ [51]. Thus, plant polysaccharide structures responsible for GM-CSF stimulation and hemagglutination appear to be distinct from each other.

Differences in intracellular signaling pathways were observed between Clerodendrum polysaccharides and previously reported immunomodulatory botanical polysaccharides. For example, polysaccharides from algae Capsosiphon fulvescens induced ERK1/2, but not p38 [52], polysaccharide SP1 from Caulerpa lentillifera increased the phosphorylation of p38 [53], whereas polysaccharide AP-1 from Platycodon grandiflorum activated phosphorylation of all three MAPKs [46]. Here, we demonstrated that CSP-AU1 induces phosphorylation of Akt2, Akt3, GSK-3 $\alpha / \beta, \mathrm{p} 38 \beta / \gamma / \delta$, p70S6K1, RSK2, and mTOR, but not ERK1/2 in human peripheral blood mononuclear cells. Thus, it appears that various immunomodulatory polysaccharides exert their biological activities through different modes of action.

Plant polysaccharides can modulate leukocyte activity via different receptors, including complement receptor 3 (CR3), scavenger receptor, dectin-1, mannose receptor, galectin 3 , and TLR4 (reviewed in [22]). For example, polysaccharides ASP and G1-4A, which were isolated from Acanthopanax senticosus and Tinospora cordifolia, respectively, activated macrophages and B cells by interacting with TLR4 [54,55]. TLR4 was also found to be one of the cellular receptors mediating TNF secretion induced by ZPF1, polysaccharide isolated from Dioscorea batatas [56]. Likewise, polysaccharide CWSP from Chlorella pyrenoidosa induced cytokine secretion in macrophages via TLR4-mediated signaling pathways [57]. In the present work, we found that the Clerodendrum polysaccharide sub-fraction CSP-AU1 induced secretion of TNF in human PBMCs mainly via TLR4, but binding affinity for this TLR agonist was much lower than that of E.coli-derived LPS. Indeed, a 10-fold higher concentration of LPS-RS over LPS was necessary to completely inhibit LPS-induced TNF production in human PBMC. In comparison, a much lower relative concentration of LPS-RS was needed to inhibit CSP-AU1 activity. Thus, the pharmacological properties of such low-affinity TLR4/ MD-2 ligands may be different than those of bacterial LPS. Indeed, although the profiles of pro-inflammatory mediators (NO and most of the cytokines studied here) for in vitro stimulatory activity by bacterial LPS and CSP-AU were fairly similar (Figures 1, 2, 3, and 6), the profile was quite different for production of GM-CSF (Figure 4). Because several plant polysaccharides were recently found having therapeutic effects in different models of autoimmune diseases, such as arthritis [31,34], lupus erythematosus-like syndrome [30,33], autoallergic mouse model of Sjogren's syndrome [58], asthma [59], and EAE [32], we suggest that such natural low-affinity TLR4 agonists may have clinically beneficial effects on autoimmune diseases by their induction of immunosuppression during chronic administration [29].

Although medical application of hot-water extracts from C. splendens for the treatment of autoimmune diseases has not been reported to date, in the present work we studied therapeutic effects of CSP-AU1 in a mouse model of EAE. We found that chronic i.p. administration of CSP-AU1 induced clinically beneficial effects in EAE, supporting the immunomodulatory properties of Clerodendrum polysaccharides in vivo. Our data showed that CSP-AU1 treatment of mice with EAE delayed disease onset and reduced the clinical severity of EAE. Only one plant polysaccharide, ginsan from Panax ginseng, has been tested to date in this animal model of multiple sclerosis [32]. Similar to our results, these authors observed reduced EAE severity. The polysaccharide ginsan also has been reported to exhibit an anti-allergic reaction in an ovalbumin-induced murine asthma model [60]. Although various plant polysaccharides have been reported to have therapeutic activity in some other models of autoimmune diseases [30,31,33,34,58], mechanisms of immune suppression by these highmolecular weight molecules in autoimmune disease remain unresolved. Because different plant polysaccharides (e.g., [61]) and CSP-AU1 activate cells, presumably via TLR4, it is possible that chronic stimulation of the innate immune system via TLR4 could lead to the induction of immunosuppression [29]. Indeed, Vaknin et al. [29] demonstrated that repetitive administration of LPS was 

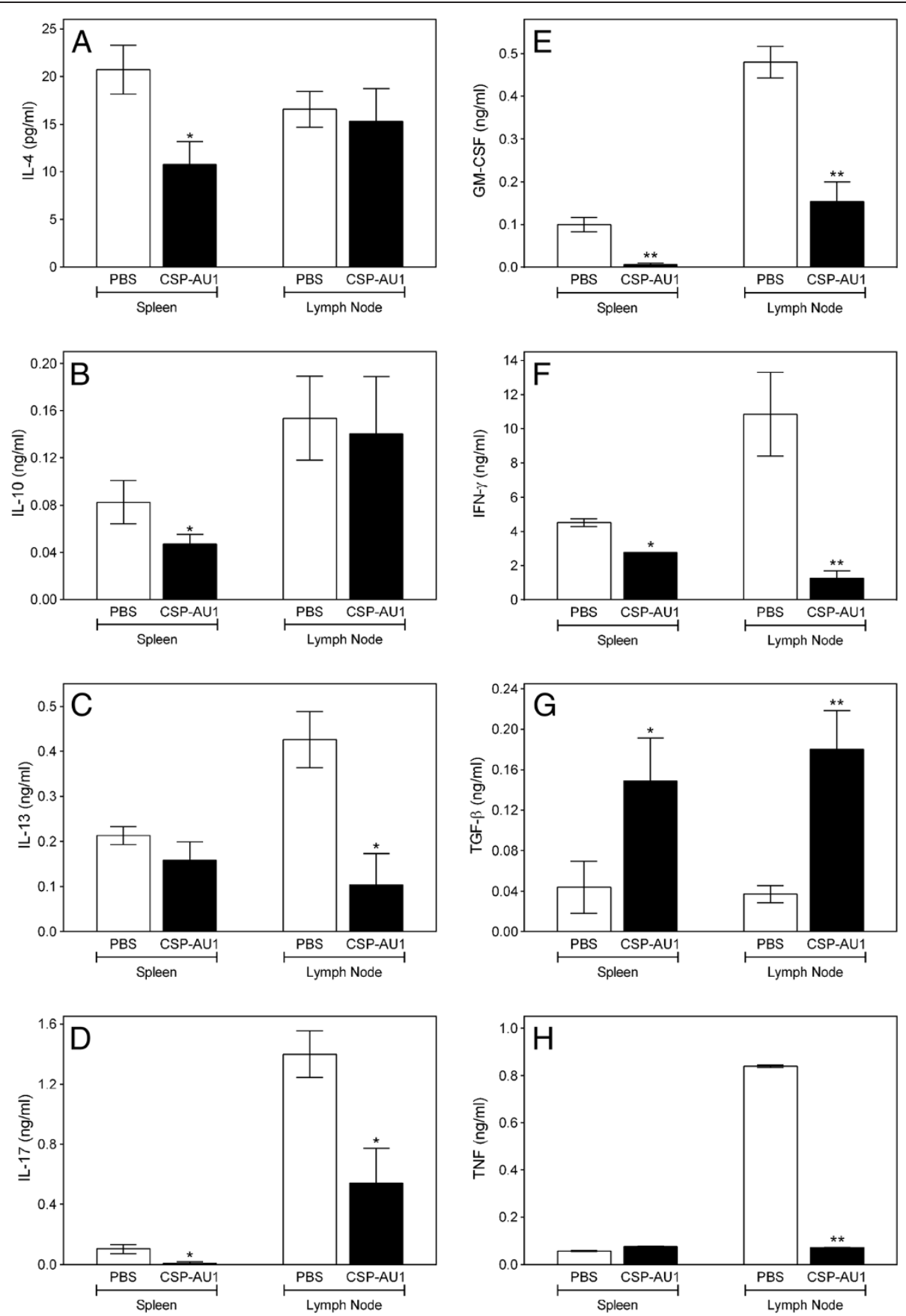

Figure 12 Cytokine profile of splenic and lymph node (LN) cells isolated from PBS- or CSP AU1-treated EAE mice. Splenic and LN cells were prepared from mice at day 17 after immunization with MOG $_{35-55}$ peptide. These cells $\left(5 \times 10^{6} \mathrm{cell} / \mathrm{ml}\right)$ were restimulated with $10 \mu \mathrm{g} / \mathrm{ml}$ $\mathrm{MOG}_{35-55}$ for 4 days, cell-free supernatants were collected, and extracellular cytokines were quantified by ELISA. Mean cytokine concentrations from 3-5 cultures \pm S.D. are shown. Statistically significant differences $\left({ }^{*} p<0.05 ;{ }^{*} p<0.001\right)$ between cells, isolated from PBS- and CSP-AU1treated EAE mice are indicated.

sufficient to induce bystander T-cell immunosuppression. Moreover, LPS-stimulated dendritic cells induced tolerance against established collagen-induced arthritis [62].

In attempts to determine possible immunomodulatory mechanisms of EAE delay by CSP-AU1, we evaluated cytokine production by MOG-peptide reactivated cells in culture, after isolation from CSP-AU1- and PBS-treated EAE mice, and found that the beneficial effect of CSPAU1 administration was accompanied by reduced IFN- $\gamma$, IL-13, IL-17, TNF, GM-CSF and increased TGF- $\beta$ production. Indeed, a review of the literature regarding immune mechanisms of multiple sclerosis and EAE showed that 
these cytokines play an important role in progression of EAE disease. In EAE, increased number of IL-17- and IFN- $\gamma$-producing cells in the spinal cord resulted from peripheral expansion of these cells after immunization with myelin-derived antigen (reviewed in [63]). During the EAE disease effector phase, GM-CSF was reported to sustain neuroinflammation via myeloid cells that infiltrated the central nervous system [64]. TNF produced by myeloid cells accelerated the onset of EAE disease by regulation of chemokine expression in the CNS, driving the recruitment of inflammatory cells into the target organ [65]. On the other hand, we recently found that regulatory $\mathrm{T}$ cells confer protection against EAE via TGF- $\beta$ [19]. Thus, the higher level of TGF- $\beta$ production by splenic and lymph node lymphocytes from CSP-AU1-treated EAE mice could be related to the beneficial therapeutic effects of this polysaccharide fraction.

\section{Conclusion}

In this study, we elucidate the molecular mechanism of monocyte/macrophage activation by polysaccharides isolated from leaves of $C$. splendens. We found that Diaion HP-20-unbound polysaccharides from C. splendens were not cytotoxic and activated PBMCs and monocyte/macrophages, resulting in stimulation of NO and cytokine production. Our data demonstrated that Clerodendrum polysaccharide sub-fraction CSP-AU1, which was one of the most potent activators of cytokine production, activated PBMCs and monocyte/macrophages via TLR4 and signaling cascades involving Akt $2 / 3$, GSK- $3 \alpha / \beta, \mathrm{p} 38 \beta$,

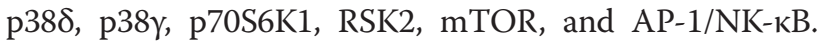
We also found that chronic i.p. administration of CSP-AU1 induced clinically beneficial effects in EAE, an experimental model of multiple sclerosis, supporting the immunomodulatory properties of Clerodendrum polysaccharides in vivo. Thus, our data provide a molecular basis to explain at least part of the beneficial therapeutic effects for hot-water extracts of $C$. splendens, and suggest that the polysaccharides from C. splendens have potential for immune modulation.

\section{Competing interests}

The authors declare that they have no competing interests concerning this article.

\section{Authors' contributions}

KK, IAS, SJ, DWP, MAJ, YSO, and MTQ designed experiments and evaluated results. KK, IAS, SJ, LNK, and DSK performed experiments. AY collected ethnopharmacological data. KK, IAS, and MTQ drafted the manuscript. KK, IAS, DWP, MAJ, YSO, and MTQ corrected the manuscript for publication. All authors read and approved the final manuscript.

\section{Acknowledgements}

We would like to thank Drs. Christopher West and Christa L. Feasley, Oklahoma Center for Medical Glycobiology Core Laboratory, Oklahoma City, OK for expert monosaccharide analysis. This work was supported in part by an Institutional Development Award (IDeA) from the National Institute of General Medical Sciences of the National Institutes of Health under grant number GM103500, National Institutes of Health grant AT04986, United States Department of State Fulbright Visiting Scholar Program (Grant ID
68110029), an equipment grant from the M. J. Murdock Charitable Trust, and the Montana State University Agricultural Experimental Station.

\section{Author details}

'Department of Immunology and Infectious Diseases, Montana State University, Bozeman, MT 59717, USA. '2Laboratoire d'Endocrinologie et Biologie de la Reproduction, Université de Cocody-Abidjan, Abidjan, Côte d'Ivoire. ${ }^{3}$ Department of Infectious Diseases and Pathology, University of Florida, Gainesville, FL 32611, USA. ${ }^{4}$ Institut National de la Santé Public, Abidjan, Côte d'Ivoire. ${ }^{5}$ Institute of Physiology, Komi Science Centre, The Urals Branch of the Russian Academy of Sciences, Syktyvkar, Russia.

Received: 22 February 2013 Accepted: 20 June 2013

Published: 28 June 2013

\section{References}

1. Venkatesha SH, Rajaiah R, Berman BM, Moudgil KD: Immunomodulation of Autoimmune Arthritis by Herbal CAM. Evid Based Complement Alternat Med 2011, 2011:986797.

2. Huang CF, Lin SS, Liao PH, Young SC, Yang CC: The immunopharmaceutical effects and mechanisms of herb medicine. Cell Mol Immunol 2008, 5(1):23-31.

3. Shrivastava N, Patel T: Clerodendrum and healthcare: an overview. Medicinal Aromatic Plant Sci Biotech 2007, 1:140-150.

4. Irvine FR: Woody Plants of Ghana. 1st edition. London: Oxford University Press; 1961:750-754.

5. Steane DA, Scotland RW, Mabberley DJ, Olmstead RG: Molecular systematics of Clerodendrum (Lamiaceae): its sequences and total evidence. Am J Bot 1999, 86(1):98-107.

6. Okwu DE, Iroabuchi F: Isolation of an antioxidant flavanone diglycoside from the Nigeria medicinal plant Clerodendron splendens, a. Cheval. Int $J$ Chem Sci 2008, 6:631-636.

7. Okwu DE, Iroabuchi F: Phytochemical composition and biological activities of Uvaria chamae and Clerodendoron splendens. E-Journal Chem 2009, 6:553-560.

8. Gbedema SY, Emelia K, Francis A, Kofi A, Eric W: Wound healing properties and kill kinetics of Clerodendron splendens G. Don, a Ghanaian wound healing plant. Pharmacognosy Res 2010, 2(2):63-68.

9. Abouzid SF, Wahba HM, Elshamy A, Cos P, Maes L, Apers S, Pieters L, Shahat AA: Antimicrobial activity of some Clerodendrum species from Egypt. Nat Prod Res 2013, 27(11):1032-1036.

10. el-Deeb KS: The volatile constituents in the absolute of Clerodendron splendens G. Don oil. Bull Fac Pharm Cairo Univ 2003, 41:259-263.

11. Shehata AH, Yousif MF, Soliman GA: Phytochemical and pharmacological investigations of Clerodendron splendens G. Don growing in Egypt. Egypt J Biomed Sci 2001, 7:145-163.

12. Pinto WJ, Nes WR: $24 \beta$-Ethylsterols, n-alkanes and n-alkanols of Clerodendron splendens. Phytochem Rev 1985, 24:1095-1097.

13. Yang H, Jiang B, Hou AJ, Lin ZW, Sun HD: Colebroside A, a new diglucoside of fatty acid ester of glycerin from Clerodendrum colebrookianum. J Asian Nat Prod Res 2000, 2(3):177-185.

14. Okwu DE, Uchenna NF: Exotic multifaceted medicinal plants of drugs and pharmaceutical industries. Afr J Biotechnol 2009, 8:7271-7282.

15. Masuko T, Minami A, Iwasaki N, Majima T, Nishimura S, Lee YC: Carbohydrate analysis by a phenol-sulfuric acid method in microplate format. Anal Biochem 2005, 339(1):69-72.

16. Yariv J, Rapport MM, Graf L: The interaction of glycosides and saccharides with antibody to the corresponding phenylazo glycosides. Biochem J $1962,85: 383-388$

17. Singleton $V L$, Rossi JA: Colorimetry of total phenolics with phosphomolybdic-phosphotungstic acid reagents. Amer J Enol Viticult 1965, 16:144-158.

18. Wood PJ, Siddiqui IR: Determination of methanol and its application to measurement of pectin ester content and pectin methyl esterase activity. Anal Biochem 1971, 39(2):418-428.

19. Jun S, Ochoa-Reparaz J, Zlotkowska D, Hoyt T, Pascual DW Bystander-mediated stimulation of proteolipid protein-specific regulatory $\mathrm{T}$ (Treg) cells confers protection against experimental autoimmune encephalomyelitis (EAE) via TGF- $\beta$. J Neuroimmunol 2012, 245(1-2):39-47 
20. Catchpole B, Hamblin AS, Staines NA: Autologous mixed lymphocyte responses in experimentally-induced arthritis of the Lewis rat. Autoimmunity 2002, 35(2):111-117.

21. Brito $L A$, Singh M: Acceptable levels of endotoxin in vaccine formulations during preclinical research. J Pharm Sci 2011, 100(1):34-37

22. Schepetkin IA, Quinn MT: Botanical polysaccharides: macrophage immunomodulation and therapeutic potential. Int Immunopharmacol 2006, 6(3):317-333.

23. Xie G, Schepetkin IA, Siemsen DW, Kirpotina LN, Wiley JA, Quinn MT Fractionation and characterization of biologically-active polysaccharides from Artemisia tripartita. Phytochemistry 2008, 69(6):1359-1371.

24. Xie G, Schepetkin IA, Quinn MT: Immunomodulatory activity of acidic polysaccharides isolated from Tanacetum vulgare L. Int Immunopharmacol 2007, 7(13):1639-1650

25. Schepetkin IA, Xie G, Kirpotina LN, Klein RA, Jutila MA, Quinn MT: Macrophage immunomodulatory activity of polysaccharides isolated from Opuntia polyacantha. Int Immunopharmacol 2008, 8(10):1455-1466.

26. Kikkert $R$, de Groot ER, Aarden LA: Cytokine induction by pyrogens: comparison of whole blood, mononuclear cells, and TLR-transfectants. $\mathrm{J}$ Immunol Methods 2008, 336(1):45-55.

27. Coats SR, Pham TT, Bainbridge BW, Reife RA, Darveau RP: MD-2 mediates the ability of tetra-acylated and penta-acylated lipopolysaccharides to antagonize Escherichia coli lipopolysaccharide at the TLR4 signaling complex. J Immunol 2005, 175(7):4490-4498.

28. Guha M, Mackman N: LPS induction of gene expression in human monocytes. Cell Signal 2001, 13(2):85-94.

29. Vaknin I, Blinder L, Wang L, Gazit R, Shapira E, Genina O, Pines M, Pikarsky E, Baniyash M: A common pathway mediated through Toll-like receptors leads to T- and natural killer-cell immunosuppression. Blood 2008, 111(3):1437-1447.

30. Wang Z, Li H, Xu H, Yue XL, Cheng XQ, Hou WJ, Zhang YY, Chen DF Beneficial effect of Bupleurum polysaccharides on autoimmune disease induced by Campylobacter jejuni in BALB/c mice. J Ethnopharmacol 2009 124(3):481-487.

31. Jiang JB, Qiu JD, Yang LH, He JP, Smith GW, Li HQ: Therapeutic effects of astragalus polysaccharides on inflammation and synovial apoptosis in rats with adjuvant-induced arthritis. Int J Rheum Dis 2010, 13(4):396-405.

32. Hwang I, Ahn G, Park E, Ha D, Song JY, Jee Y: An acidic polysaccharide of Panax ginseng ameliorates experimental autoimmune encephalomyelitis and induces regulatory T cells. Immunol Lett 2011, 138(2):169-178.

33. Jiang YW, Li H, Zhang YY, Li W, Jiang YF, Ou YY, Chen DF: Beneficial effect of Bupleurum polysaccharides on autoimmune-prone MRL-Ipr mice. Clin Dev Immunol 2012, 2012:842928.

34. Suszko A, Obminska-Mrukowicz B: Influence of polysaccharide fractions isolated from Caltha palustris L. on the cellular immune response in collagen-induced arthritis $(\mathrm{CIA})$ in mice. A comparison with methotrexate. J Ethnopharmacol 2013, 145(1):109-117.

35. Batoulis $\mathrm{H}$, Addicks $\mathrm{K}$, Kuerten S: Emerging concepts in autoimmune encephalomyelitis beyond the $\mathrm{CD} 4 / \mathrm{T}(\mathrm{H}) 1$ paradigm. Ann Anat 2010, 192(4):179-193.

36. Schepetkin IA, Faulkner CL, Nelson-Overton LK, Wiley JA, Quinn MT: Macrophage immunomodulatory activity of polysaccharides isolated from Juniperus scopolorum. Int Immunopharmacol 2005, 5(13-14):1783-1799.

37. Popov SV, Golovchenko W, Ovodova RG, Smirnov W, Khramova DS, Popova GY, Ovodov YS: Characterisation of the oral adjuvant effect of lemnan, a pectic polysaccharide of Lemna minor L. Vaccine 2006, 24(26):5413-5419.

38. Popov SV, Vinter VG, Patova OA, Markov PA, Nikitina IR, Ovodova RG, Popova GY, Shashkov AS, Ovodov YS: Chemical characterization and antiinflammatory effect of rauvolfian, a pectic polysaccharide of Rauvolfia callus. Biochemistry (Mosc) 2007, 72(7):778-784.

39. Takeuchi A, Kamiryou Y, Yamada H, Eto M, Shibata K, Haruna K, Naito S, Yoshikai Y: Oral administration of xanthan gum enhances antitumor activity through Toll-like receptor 4. Int Immunopharmacol 2009, 9(13-14):1562-1567.

40. Khramova DS, Popov SV, Golovchenko W, Vityazev FV, Paderin NM, Ovodov YS: Abrogation of the oral tolerance to ovalbumin in mice by citrus pectin. Nutrition 2009, 25(2):226-232.

41. Ramberg JE, Nelson ED, Sinnott RA: Immunomodulatory dietary polysaccharides: a systematic review of the literature. Nutrition 2010, 9:54.

42. Smiderle FR, Ruthes AC, Van AJ, Chanput W, lacomini M, Wichers HJ, Van Griensven LJ: Polysaccharides from Agaricus bisporus and Agaricus brasiliensis show similarities in their structures and their immunomodulatory effects on human monocytic THP-1 cells. BMC Complement Altern Med 2011, 11:58

43. Skyberg JA, Rollins MF, Holderness JS, Marlenee NL, Schepetkin IA, Goodyear A, Dow SW, Jutila MA, Pascual DW: Nasal Acai polysaccharides potentiate innate immunity to protect against pulmonary Francisella tularensis and Burkholderia pseudomallei Infections. PLoS Pathog 2012, 8(3):e1002587.

44. Holderness J, Schepetkin IA, Freedman B, Kirpotina LN, Quinn MT, Hedges $J F$, Jutila MA: Polysaccharides isolated from Acai fruit induce innate immune responses. PLoS One 2011, 6(2):e17301.

45. Renard CM, Baron A, Guyot S, Drilleau JF: Interactions between apple cell walls and native apple polyphenols: quantification and some consequences. Int JBiol Macromol 2001, 29(2):115-125.

46. Yoon YD, Kang JS, Han SB, Park SK, Lee HS, Kang JS, Kim HM: Activation of mitogen-activated protein kinases and AP-1 by polysaccharide isolated from the radix of Platycodon grandiflorum in RAW 264.7 cells. Int Immunopharmacol 2004, 4(12):1477-1487.

47. Salman H, Bergman M, Djaldetti M, Orlin J, Bessler H: Citrus pectin affects cytokine production by human peripheral blood mononuclear cells. Biomed Pharmacother 2008, 62(9):579-582.

48. Ramachandran C, Wilk BJ, Hotchkiss A, Chau H, Eliaz I, Melnick SJ: Activation of human T-helper/inducer cell, T-cytotoxic cell, B-cell, and natural killer (NK)-cells and induction of natural killer cell activity against K562 chronic myeloid leukemia cells with modified citrus pectin. BMC Complement Altern Med 2011, 11:59.

49. Popov SV, Markov PA, Popova GY, Nikitina IR, Efimova L, Ovodov YS: Antiinflammatory activity of low and high methoxylated citrus pectins. Biomed Prevent Nutr 2013, 3:59-63.

50. Kouakou K, Schepetkin IA, Yapi A, Kirpotina LN, Jutila MA, Quinn MT: Immunomodulatory activity of polysaccharides isolated from Alchornea cordifolia. J Ethnopharmacol 2013, 146(1):232-242.

51. Schepetkin IA, Kouakou K, Yapi A, Kirpotina LN, Jutila MA, Quinn MT: Immunomodulatory and hemagglutinating activities of acidic polysaccharides isolated from Combretum racemosum. Int Immunopharmacol 2013, 15:628-637.

52. Go H, Hwang HJ, Nam TJ: Polysaccharides from Capsosiphon fulvescen stimulate the growth of IEC- 6 Cells by activating the MAPK signaling pathway. Mar Biotechnol 2011, 13(3):433-440.

53. Maeda R, Ida T, Ihara H, Sakamoto T: Immunostimulatory activity of polysaccharides isolated from Caulerpa lentillifera on macrophage cells. Biosci Biotechnol Biochem 2012, 76(3):501-505.

54. Han SB, Yoon YD, Ahn HJ, Lee HS, Lee CW, Yoon WK, Park SK, Kim HM: Tolllike receptor-mediated activation of $B$ cells and macrophages by polysaccharide isolated from cell culture of Acanthopanax senticosus. Int Immunopharmacol 2003, 3(9):1301-1312.

55. Raghu R, Sharma D, Ramakrishnan R, Khanam S, Chintalwar GJ, Sainis KB: Molecular events in the activation of $B$ cells and macrophages by a nonmicrobial TLR4 agonist, G1-4A from Tinospora cordifolia. Immunol Lett 2009, 123(1):60-71

56. Liu JY, Yang FL, Lu CP, Yang YL, Wen CL, Hua KF, Wu SH: Polysaccharides from Dioscorea batatas induce tumor necrosis factor-alpha secretion via Toll-like receptor 4-mediated protein kinase signaling pathways. J Agric Food Chem 2008, 56(21):9892-9898

57. Hsu HY, Jeyashoke N, Yeh CH, Song YJ, Hua KF, Chao LK: Immunostimulatory bioactivity of algal polysaccharides from Chlorella pyrenoidosa activates macrophages via Toll-like receptor 4. J Agric Food Chem 2010, 58(2):927-936.

58. Wang Y, Yan T, Shen J, Guo H, Xiang X: Preventive effect of Ophiopogon japonicus polysaccharides on an autoallergic mouse model for Sjogren's syndrome by regulating the Th1/Th2 cytokine imbalance. J Ethnopharmacol 2007, 114(2):246-253.

59. Jung ID, Kim HY, Park JW, Lee CM, Noh KT, Kang HK, Heo DR, Lee SJ, Son $\mathrm{KH}$, Park HJ, et al: RG-II from Panax ginseng C.A. Meyer suppresses asthmatic reaction. BMB Rep 2012, 45(2):79-84.

60. Lim YJ, Na HS, Yun YS, Choi IS, Oh JS, Rhee JH, Cho BH, Lee HC: Suppressive effects of ginsan on the development of allergic reaction in murine asthmatic model. Int Arch Allergy Immunol 2009 150(1):32-42.

61. Schepetkin IA, Quinn MT: Immunomodulatory effects of botanical polysaccharides. In Polysaccharides in Medicinal and Pharmaceutical 
Applications. 35th edition. Edited by Popa V. Shawbury, UK: Smithers Rapra; 2011:988-994.

62. Salazar L, Aravena O, Abello P, Escobar A, Contreras-Levicoy J, RojasColonelli N, Catalan D, Aguirre A, Zuniga R, Pesce B, et al: Modulation of established murine collagen-induced arthritis by a single inoculation of short-term lipopolysaccharide-stimulated dendritic cells. Ann Rheum Dis 2008, 67(9):1235-1241.

63. Petermann F, Korn T: Cytokines and effector T cell subsets causing autoimmune CNS disease. FEBS Lett 2011, 585(23):3747-3757.

64. Codarri L, Gyulveszi G, Tosevski V, Hesske L, Fontana A, Magnenat L, Suter T, Becher B: RORyt drives production of the cytokine GM-CSF in helper T cells, which is essential for the effector phase of autoimmune neuroinflammation. Nat Immunol 2011, 12(6):560-567.

65. Kruglov AA, Lampropoulou V, Fillatreau S, Nedospasov SA: Pathogenic and protective functions of TNF in neuroinflammation are defined by its expression in T lymphocytes and myeloid cells. J Immunol 2011, 187(11):5660-5670.

doi:10.1186/1472-6882-13-149

Cite this article as: Kouakou et al: Immunomodulatory activity of polysaccharides isolated from Clerodendrum splendens: Beneficial effects in experimental autoimmune encephalomyelitis. BMC Complementary and Alternative Medicine 2013 13:149.

\section{Submit your next manuscript to BioMed Central and take full advantage of:}

- Convenient online submission

- Thorough peer review

- No space constraints or color figure charges

- Immediate publication on acceptance

- Inclusion in PubMed, CAS, Scopus and Google Scholar

- Research which is freely available for redistribution 